Review

\title{
Nucleic Acid Aptamers: An Emerging Tool for Biotechnology and Biomedical Sensing
}

\author{
Ti-Hsuan Ku ${ }^{1}$, Tiantian Zhang ${ }^{2}$, Hua Luo ${ }^{1,3,4}$, Tony M. Yen ${ }^{5}$, Ping-Wei Chen ${ }^{6}$, \\ Yuanyuan Han ${ }^{1}$ and Yu-Hwa Lo ${ }^{1, *}$
}

1 Department of Electrical and Computer Engineering, University of California San Diego, La Jolla, CA 92093-0407, USA; E-Mails: tiku@eng.ucsd.edu (T.-H.K.); luohuabox@gmail.com (H.L.); yuh054@ucsd.edu (Y.H.)

2 Materials Science and Engineering Program, University of California San Diego, La Jolla, CA 92093-0418, USA; E-Mail: tiz022@eng.ucsd.edu

3 College of Basic Medicine and Forensic Medicine, Sichuan University, Chengdu 610041, China

4 College of Manufacturing Science and Engineering, Sichuan University, Chengdu 610041, China

5 Department of Bioengineering, University of California San Diego, La Jolla, CA 92093-0412, USA; E-Mail: tmyen@eng.ucsd.edu

6 Chemical Engineering Program, University of California San Diego, La Jolla, CA 92093-0448, USA; E-Mail: pingwei320@gmail.com

* Author to whom correspondence should be addressed; E-Mail: ylo@ece.ucsd.edu; Tel.: +1-858-822-3429; Fax: +1-858-534-0556.

Academic Editor: Yeshaiahu Fainman

Received: 25 April 2015 / Accepted: 30 June 2015 / Published: 6 July 2015

\begin{abstract}
Detection of small molecules or proteins of living cells provides an exceptional opportunity to study genetic variations and functions, cellular behaviors, and various diseases including cancer and microbial infections. Our aim in this review is to give an overview of selected research activities related to nucleic acid-based aptamer techniques that have been reported in the past two decades. Limitations of aptamers and possible approaches to overcome these limitations are also discussed.
\end{abstract}

Keywords: DNA; RNA; aptamer; SELEX; biomarkers; polymer; liposome 


\section{Introduction}

Aptamers are short single-stranded DNA- or RNA-based oligonucleotides that can selectively bind to small molecular ligands or protein targets with high affinity and specificity, when folded into their unique three-dimensional structures. They have been first reported more than 20 years ago by Ellington and Gold [1,2]. Ellington reported a selection of RNA molecules that specifically bind to organic dyes, and Gold reported an RNA ligand that interacts with T4 DNA polymerase. Several aptamers have been identified for different targets as diagnostic tools and disease treatment drugs. There is an intense interest and ever increasing need within basic and clinical sciences to detect, analyze and quantify these small molecules and proteins utilizing aptamers. Over 1000 papers related to aptamers have been published each year since 2010, attesting the wide applicability and great potential of aptamers. Figure 1 indicates a large number of scientific publications in this active field of research.

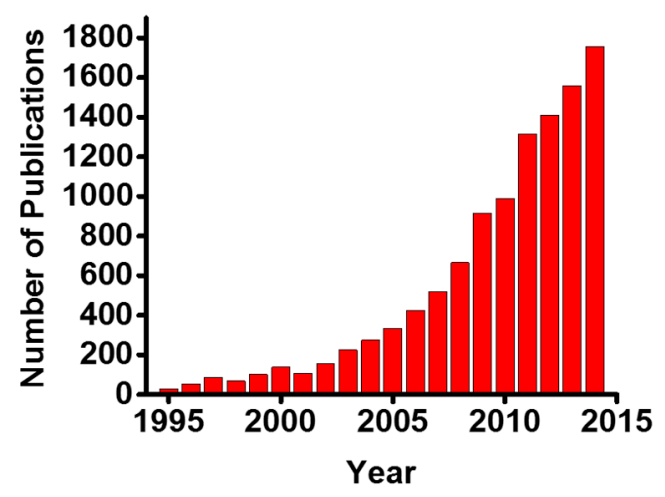

Figure 1. The annual trends in the number of publications of aptamers-related research. The term "aptamer" has been utilized for literature search on Thomson Reuters Web of Science.

\section{Aptamer Properties}

The word "aptamer" was derived from the Latin aptus — meaning "to fit", and Greek meros — meaning "region" [1]. Nucleic acid aptamers are single strands of DNA or RNA (and chemically-modified DNA or RNA) with a length in the range of 10-100 nucleotides (nt), which are identified from an in vitro selection process: "systemic evolution of ligands by exponential enrichment (SELEX)" [2]. Over multiple rounds, the SELEX process allows isolation of functional oligonucleotide sequences that can recognize a specific target from a random single-stranded (ss)DNA or RNA library. Within the nucleic acid library, some sequences are folded into unique three-dimensional structures, possessing a combination of loops, stems, hairpins, pseudoknots, bulges, or G-quadruplexes [3-6]. The aptamer-target recognition was through intermolecular interactions such as aromatic rings, pi-pi system stacking, van der Waals and electrostatic interactions between charged groups and hydrogen bonding. Sometimes it requires the aptamer to undergo adaptive conformational changes and have their three-dimensional structure folded to a unique binding conformation for its target. Aptamers have high target chemical structure specificity, which makes it possible to discriminate a specific molecule from its analogues. Theophylline, a methylxanthine drug, is used for respiratory diseases treatment such as chronic obstructive pulmonary disease (COPD) and asthma. Because of its narrow therapeutic index, serum levels must be monitored carefully to avoid life-threatening toxicity [7]. Theophylline is chemically 
similar to caffeine, which is present in serum samples. Thus, diagnostic methods must discriminate efficiently among these compounds. The theophylline-binding aptamer shows an affinity for its cognate ligand 10,000-fold higher than that of caffeine, which differs from theophylline by only a single methyl group at nitrogen atom N-7. Enantioselective, a low molecular weight aptamer shows 12,000-fold stronger affinity with $L$-arginine than with $D$-arginine. Figure 2 shows the chemical structures of those small molecules mentioned above [8,9].<smiles>Cn1c(=O)c2c(ncn2C)n(C)c1=O</smiles>

Caffeine<smiles>Cn1c(=O)c2[nH]cnc2n(C)c1=O</smiles>

Theophylline

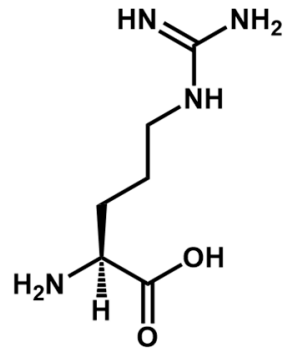

L-arginine

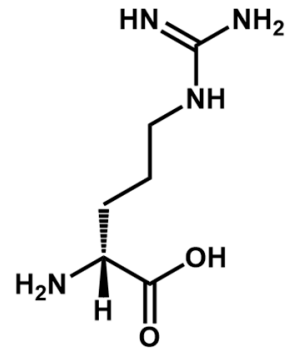

D-arginine

Figure 2. Chemical structure of theophylline, caffeine, $L$-arginine and $D$-arginine.

Beyond those features, aptamers have shown a number of extraordinary promises as molecular recognition elements in bioanalytical applications. First, due to their thermal stability, aptamers are easy to process and handle. After heat denaturation, the activity and functionality of aptamers can be easily restored within a few minutes since aptamers can undergo reversible denaturation [10-12]. Second, unlike amino acid-based receptors such as oligopeptides and antibodies, nucleic acid aptamers can not only be easily amplified by Taq polymerase-dependent polymerase chain reaction (PCR) [13], but also be readily produced by chemical synthesis [14-16]. In addition, aptamers can be easily modified by reporter molecules, linkers, and different functional groups on both the phosphate/ribose backbone and the nucleobases to improve resistance to enzymatic degradation, reduce off-target events [17-25], and be immobilized on solid-phase substrates or beads for various applications [26-29]. Moreover, aptamers can also be expressed in vivo when the cells contain plasmids that encode an aptamer sequence [30-34]. Lastly, one of the most important advantages of using an aptamer as a probe is that the technique requires no animals or in vivo immunization, thus minimizing batch-to-batch variations $[35,36]$.

Aptamer-based biosensors have not only been proven on protein targets for biomedical diagnostic applications, but also been demonstrated with organic and inorganic small molecule compounds, drugs, and antibiotics.

\section{Generation of Aptamers}

The selection of aptamers involves two steps: upstream screening and downstream truncation. The first step is to discover the full-length aptamers from the single-stranded DNA or RNA libraries through the SELEX process. The second is to identify the minimal and essential nucleotides of the full-length aptamers for the target molecule binding. 


\subsection{General Process for Aptamer Screening}

Through SELEX process, aptamers have been explored extensively as specific and high affinity probes to a variety of targets, ranging from small organic molecules dyes to large biomolecules such as proteins, cells and even entire tumor tissue [8,9,37-54]. The whole process starts from generating a randomized nucleic acid (DNA or RNA) sequence library, which is normally composed of $\sim 10^{15}$ different aptamers sequences that theoretically can recognize any target molecules [1,2]. Because the efficiency of phosphoramidite chemistry for A, T, G, and C coupling reaction is very similar, the randomized ssDNA library can be generated through a regular DNA synthesizer by using a mixture of phosphoramidites in a ratio of 1.5:1.25:1.15:1.0 (A:C:G:T) [55]. The diversity of the library is determined by the length of random sequence regions at the center flanked by designed primer binding sites at the $5^{\prime}$ and $3^{\prime}$ ends. Even though one can generate $4^{\mathrm{n}}$ different sequences from $\mathrm{n}$ nucleotides in principle, about $\sim 10^{15}$ aptamer combinations can be produced in the library, in practice, corresponding to a random region length of about 25 nucleotides. Figure 3 depicts a typical SELEX process flow, including repetition selection cycle and amplification.

The SELEX procedure consists of binding, partition, elution, and amplification. The starting point of a basic process is synthesizing an oligonucleotide sequences pool. Each sequence in this library has a central randomized sequence (20-80 nucleotides) flanked by fixed primer binding sites (18-21 nucleotides) for PCR amplification. Once the library is created, the library pool is incubated with the target molecule. Some of these oligonucleotides in the library will bind to the target and are then considered aptamers. Unbound nucleic acids are filtered out of the solution, and the bound nucleic acids are separated from the target-This is called elution. Lastly, the binding oligonucleotides are then amplified using PCR to create a new library. Artificial or chemically modified oligonucleotide bases were often used in SELEX experiments to increase the complexity of the library, to introduce new features like functional groups providing new possibilities for the interaction with target molecules, or to enhance the stability by increasing the resistance to nucleases. For example, Wang and co-workers have raised boronic acid modified aptamer for the specific recognition of the glycosylation site(s) of a glycoprotein [56], while Sawai and co-workers adjusted DNA aptamers by using the protonated amino group at the $\mathrm{C}_{5}$ position to enhance the binding affinity with the sialyllactose [57]. Generally, in RNA aptamers, the chemical modification of the sugar is realized at the level of the $2^{\prime}-\mathrm{OH}$ group of the ribose $\left(2^{\prime}-\mathrm{NH} 2,2^{\prime}\right.$-fluro, or $2^{\prime}$-O-methyl) [58,59]. These modifications could significantly improve aptamer stability for in vivo application [60,61]. Spiegelmers, chemically synthesized L-ribonucleic acid-based RNA-like aptamers, are highly considered to be resistant to degradation by nucleases and have shown to be stable over $60 \mathrm{~h}$ in biological fluid [62,63]. Three spiegelmer candidates are considered as potential drugs and are currently being tested in clinical trials [64]. In the first round of SELEX selection, the oligonucleotide library and target molecules are incubated for binding. (In this step, the ssDNA oligonucleotide library may be in vitro transcribed into a RNA library for SELEX selection if RNA aptamer selection is needed.) During the incubation stage, the target molecules interact with the aptamer library either as a free form or a form that is immobilized on a solid support substrate surface. The fixation of target molecules on a solid support surface helps easy separation of bound nucleic acids to target from unbound or weakly bound nucleic acids. However, the immobilization of the target molecules may result in molecular structure or conformation changes and cause interference on the aptamer library and target molecules 
binding [65]. The aptamer-target complex formation is followed by partitioning from unbound and weakly bound oligonucleotides, which are removed through several washing steps. This is an important step to screen high binding affinity aptamers from the library pool. The elution of the strong bound nucleic acid aptamers from the target molecules might be difficult, especially through the affinity chromatography type method. The applicability of the method might be restricted to isolation of the aptamers possessing extremely high affinity $[66,67]$. The target bound oligonucleotides are eluted and followed by PCR or RT-PCR amplification. As a result, an enriched selected oligonucleotide pool is generated from the PCR products and this pool will be used for the next SELEX selection cycle. Typically, 6-20 selection cycles are needed to identify and isolate target specific and high affinity aptamers $[68,69]$. The last SELEX selection cycle ends at the amplification step and the enriched aptamer pool is cloned for further analysis and post-SELEX modifications to improve the functionality.

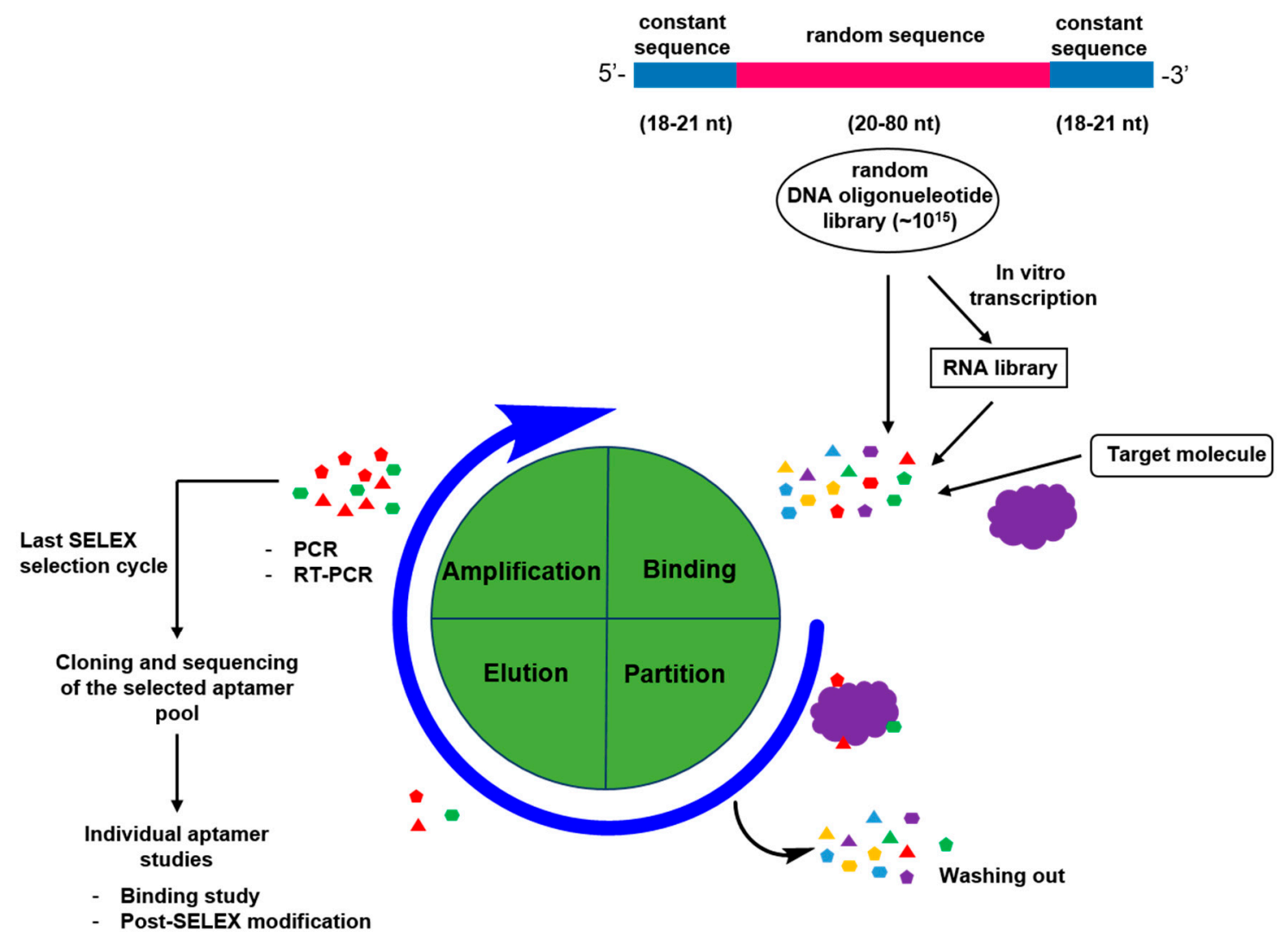

Figure 3. In vitro selection of target specific aptamer through SELEX screening process.

\subsection{Cell-SELEX: Aptamers for Cell Membrane Analysis}

The cell membrane is complex and contains various molecules, lipids, carbohydrates, and proteins, which play critical roles in cellular behaviors and activities. The composition, structure, and modification of those biomolecules may be different among cell types and between normal and abnormal cells. Discrimination and unveiling of the cell membrane changes and differences are critical for disease diagnosis, treatment and drug design.

Compared to pure target molecules like small molecule organic dyes or proteins, cell membrane is a very complex target system. Cell-SELEX identifies aptamers that specifically bind to a certain cell type 
based on unique cell membrane extracellular characteristics. As a result, this method requires no cell surface biomarker information prior to the experiment. In 1998, Gold group [39] reported the first experiment using cell membrane as a selection target. They used red blood cell to bind aptamer library and demonstrated that SELEX method could be used not only on pure molecules, but also on complex objects such as whole cells. Recently, cell-SELEX has been further utilized for cancer research, which is particularly useful for identifying subtle cell proteomic changes between normal and cancerous cells. The positive selection on cancer cells, and negative selection on normal cells, can reveal molecular differences among the proteins. Shao group [70] has performed cell-SELEX experiment on paraffin-embedded carcinoma tissue samples. This selection process generated an aptamer, BC 15, which can specifically recognize breast cancer cells which express hnRNP A1 protein. The aptamer works for both MCF-7 cell line and clinical samples. The general aptamer screening procedure of cell-SELEX is shown in Figure 4.

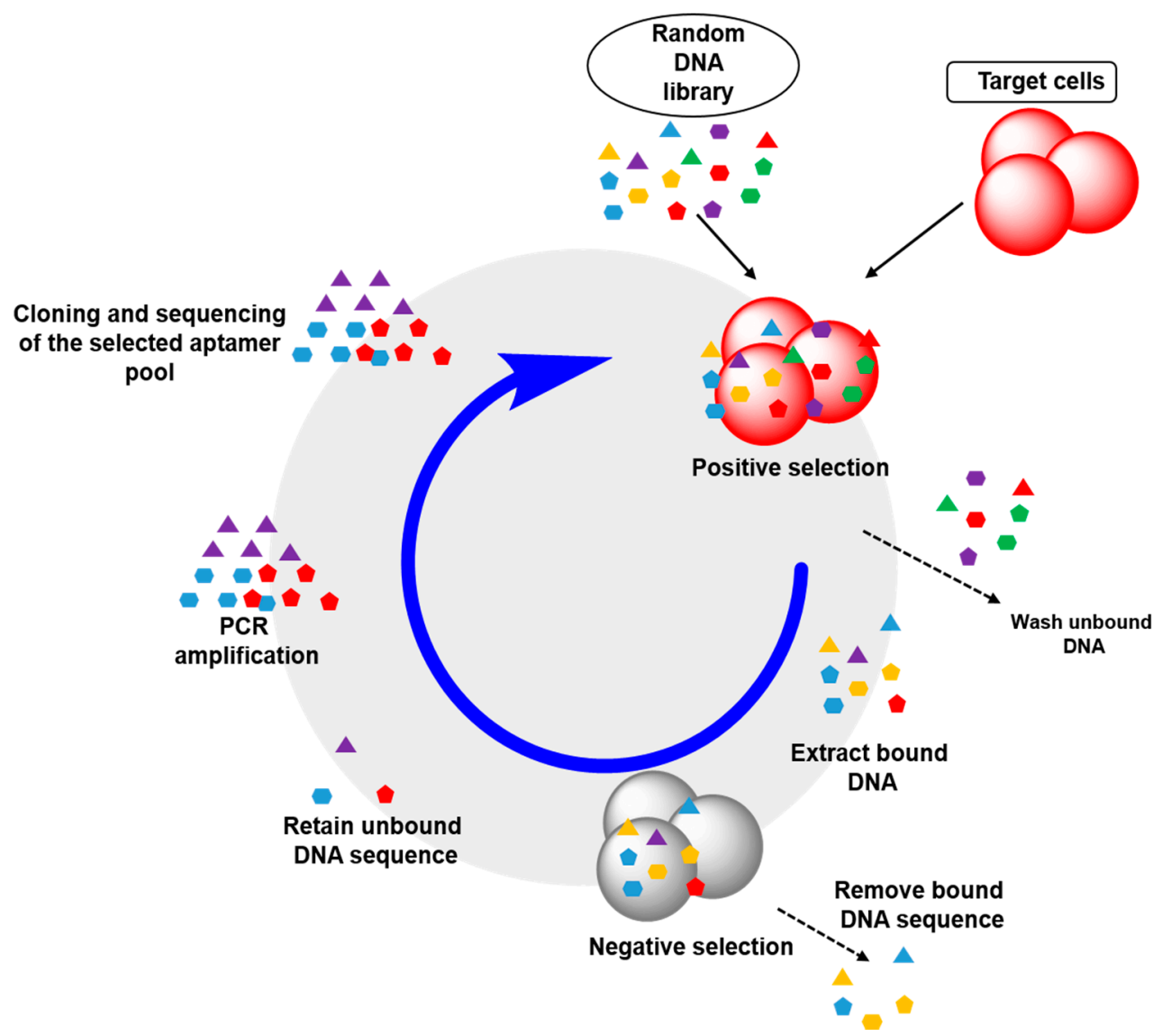

Figure 4. Scheme of cell-SELEX screening process.

\subsection{Aptamer Truncation}

A full length aptamer selected from nucleic acid libraries is generally $\sim 80$ nucleotides long but the region that plays the role of target contacting is usually 10-15 nucleotides [71,72]. In certain conditions, the existence of nonessential nucleotides could interfere with the aptamer and target molecule binding [73]. Thus, the redundant and nonessential nucleotides should be eliminated. Many strategies have been employed for probing and minimizing oligonucleotide sequences length without losing the high binding affinity. Computational algorithms were used to predict the truncated aptamer sequences 
and secondary structures. For example, Giangrande and co-workers have used a "rational truncation" approach guided by RNA structure prediction and RNA/target docking algorithms to truncate an RNA aptamer to prostate-specific membrane antigen (PSMA), which retains protein binding activity and functionality [74-80]. Other techniques such as partial fragmentation were used to determine the minimal binding sequence of DNA aptamers for platelet-derived growth factor (PDGF) protein [81]. DNase I footprinting analysis was used to reveal the prion protein $(\mathrm{PrP})$ binding region of selected DNA aptamers [82,83]. Also microarray based quantitative and high-throughput binding sequence determination strategy was employed to select aptamers for immunoglobulin E ( $\mathrm{IgE}$ ) and human cancer biomarker angiopoietin-2 (Ang2) [84,85]. However, the usefulness of those elegant approaches is compromised since they are expensive, complicated for operation, and time-consuming. Recently, the hybridization inhibition approach was developed to identify the minimal binding sequences. Wang and co-workers used the complementary oligonucleotide probes to hybridize with the nonessential region of the anti-human protein tyrosine kinase 7 (hPTK7) aptamer to generate truncated aptamers [73]; Duan and co-workers used the same approach to generate truncated aptamer for CD133 marker of cancer stem cell [86].

\section{Aptamers as Sensors for Biomarker Discovery}

Biomarkers indicate disease pathogenesis progression state, the risk of a particular disease, and the change of gene or protein expression level when physiological conditions change. Biomarkers can have multiple forms, among which proteins and unique genomic DNA sequences are the most popular ones. For example, HER2/neu gene expression level could be used to predict a patient's response to breast cancer treatment, while the BRCA1 gene mutation could be used to estimate breast cancer development risk [87-89]. However, a very limited number of biomarkers have been used clinically and novel biomarker discovery methods are needed to improve their use in clinical stages. Conventional approaches for biomarker discovery use mass spectrometry or monoclonal antibody (mAb), which enables researchers to analyze the cellular proteome or metabolome and identify disease specific molecules or metabolites $[35,36,90,91]$. However, membrane proteins are still hard to tackle. mAb has been utilized to validate biomarkers by specifically recognizing proteins that are significantly expressed in diseased or abnormal cells. However, mAb requires a lot of information regarding the target molecules. Developing a mAb for a specific cell type with unknown protein epitopes is nearly impossible by the standard antibody development procedure. Compared with $\mathrm{mAb}$, aptamers are able to target cells through the exponential enrichment process, which generates a highly specific DNA sequence by multiple rounds of selection.

The general practice in aptamer-assisted biomarker discovery is based on the following steps. First, the target cells have to be amplified, collected and lysed. The cell components like cell debris or membrane proteins are incubated with biotinylated aptamers and subsequently the biomolecule-aptamer complex is isolated by streptavidin-coated resin or magnetic beads, and the bounded proteins are eluted and characterized by SDS-PAGE. The aptamer binding protein band is excised, enzymatically digested and analyzed by mass spectrometry for protein identification. Lastly, the identified protein target is further confirmed by an existing and known antibody. Using the cell-SELEX screening method, many research groups have found aptamers that specifically bind to different membrane proteins such as tyrosine kinase 
7 from T-cell acute lymphoblastic leukemia, tenascin-C from glioblastoma cells, immunoglobulin heavy $\mu(\mathrm{mu})$ chain from Burkitt's lymphoma cells and Stress-Induced Phosphoprotein 1 from ovarian cancer [41,92-94]. Although this selection approach has been effectively demonstrated to discover molecules as biomarker candidates, the identified protein targets still need to be further characterized and validated with clinical evidences to prove their viability as biomarkers.

\section{Aptamers as Molecular Imaging Probes}

\subsection{Aptamer-Based Molecular Beacons}

The first molecular beacon was introduced to recognize and report the presence of specific nucleic acid target in a homogeneous solution by Tyagi and co-workers [95]. A single-stranded DNA or RNA probe sequence, carrying complementary bases at the $5^{\prime}$ and $3^{\prime}$ end, was labeled at the terminal positions with a fluorescent moiety and a quencher. A stem-and-loop structure was formed within the molecule and the loop portion of the molecule is a probe sequence that is complementary to the target nucleic acid. On the other hand, the resulting close proximity of the stem led to fluorescence quenching. When the specific complementary target was present and hybridized to the loop, the beacon underwent a spontaneous fluorogenic conformational change and the loop separated the fluorophore and the quencher, generating a fluorescence signal to be detected. Inspired by the molecular beacon approach for DNA sequence detection, Tan and co-workers applied this to study protein-DNA interactions and for protein bioanalysis. The interaction between single-stranded DNA binding protein (SSB) and molecular beacon results in significant restoration of the fluorescence of the molecular beacon [96]. Stanton and co-workers utilized this approach for thrombin detection and termed this strategy as "aptamer beacon". Similar to the molecular beacon, the aptamer beacon possesses two or more conformations, one of which allows target protein binding. A thrombin aptamer was engineered by adding nucleotides to the $5^{\prime}$-end, which are complementary to nucleotides at the 3 '-end of the aptamer, forming a stem-loop structure. In the presence of thrombin, the aptamer beacon formed the target-binding structure and the binding of thrombin induced conformational change of the aptamer, which increased the distance between the fluorophore and the quencher and therefore produced fluorescence signal. This assay might be interfered by nonspecific protein binding (e.g., SSB protein) [97]. This is a standard signal "turn-on" approach, essentially based on target recognition and fluorescence enhancement detection. A fluorescence signal quench "turn-off" approach for real-time thrombin detection was further developed by Tan and co-workers. Significant fluorescent signal change was observed when the thrombin aptamer beacon was bound to target, which was attributed to a significant conformational change in the beacon from a loose random coil to a compact unimolecular quadruplex [98]. To prevent undesirable target-beacon interactions or fluorescence quenching in the aptamer sequence, some prior knowledge of the prediction of secondary or tertiary structures of the aptamer beacon are usually required. To overcome this limitation, Li and Nutiu reported a "structure-switching signaling aptamer". They designed an aptamer-based fluorescent reporter that functions by switching structures from DNA/DNA duplex to DNA/target complex. The fluorophore was originally quenched when no thrombin was present. When the thrombin is present, there is an aptamer structure switching. Upon binding, the aptamer releases the quencher and the fluorescence signal is restored [99]. This approach was further applied for real-time activation and amplification for 
fluorescence imaging and targeting therapy. Chu and co-workers developed an activatable theranostic beacon by using a structure-switching aptamer triggered hybridization chain reaction (HCR) on the cell surface. The HCR not only amplifies fluorescence signals from a fluorescence-quenched probe for activatable tumor imaging but also accumulates high-load prodrugs from a drug-labeled probe and induces its uptake and conversion into cisplatin in cells for selective tumor therapy [100]. More aptamer beacons were designed and reported based on the above concept. Aptamer beacon labeled quantum-dot was designed for detection of proteins, cancer cell imaging and therapy, drug and viral DNA sensing [100-103]. Gold nanoparticle (AuNP)-based colorimetric or Förster resonance energy transfer (FRET) methods have been recently developed for many analytes because of the ease of detection, high sensitivity, and potential for high-throughput analysis [104-108].

\subsection{Optical Molecular Imaging with Aptamer-Based Probes}

Optical molecular imaging, including fluorescence and bioluminescence enables visualization of molecular processes on the cellular or tissue level in small animals. It is a key modality to understand physiological or disease processes and provide invaluable information and insight to disease treatment. Aptamer probes have been designed to be activated by specific stimuli or environmental conditions. When the target is present, the aptamer binds to its target and goes through the conformational change, which allows emission of optical signals.

Like antibody-based molecular probes such as enzyme-linked immunosorbent assay (ELISA) and Immunohistochemistry stain (IHC), aptamers can also be used for biomedical and clinical research [109-112]. Moreover, aptamers have several additional advantages over antibodies as molecular probes. First, aptamers are much smaller molecules than antibodies. The molecular weight of aptamers are usually between 6 and $30 \mathrm{kDa}$, much smaller than that of antibodies ( 150 kDa) [113,114]. Its smaller size can yield greater tissue penetration ability. Second, aptamers are folded into their unique three-dimensional structures spontaneously, making them more resistant to $\mathrm{pH}$, temperature, or other environmental changes than antibodies. In contrast, once antibodies have been denatured, they usually cannot regain their original structure, thus losing their target recognition and binding ability. In addition, the superior chemical stability of aptamers allows them to be more easily modified through traditional chemical means than antibodies. Finally, unlike antibody probes, aptamers are synthesized chemically without any in vivo process, which improves their reproducibility and reliability.

Aptamers have no optical properties by themselves, so they have to be labeled with fluorophores, fluorescent quantum dots, contrast agents like radioisotope-containing compounds, or paramagnetic iron oxide nanoparticles for imaging purpose [115-118]. Fluorescent dyes can be easily conjugated to either $5^{\prime}$ or $3^{\prime}$ ends of the aptamer molecules by phosphoramidite chemistry. For in vivo imaging, fluorescent dye labeled aptamers can circulate in the model animal until binding to the specific cells or tissue. In 1997, aptamers were first demonstrated as imaging probes for in vivo study to find the rat inflammation tissue by researchers from NeXstar Pharmaceuticals. The technetium-99m $\left.{ }^{99 \mathrm{~m}} \mathrm{Tc}\right)$-labeled aptamer was selected and targeted at human neutrophil elastase to image inflammation areas. When compared with a radiolabeled $\mathrm{IgG}$, the aptamers probe provides higher signal-to noise $(\mathrm{S} / \mathrm{N})$ ratio [119].

The aptamers-based molecular imaging probes have been used to image disease associated biomarkers such as integrins, prostate-specific membrane antigen (PSMA), and nucleolin [120-123]. 
Wang group reported an activatable aptamer probe (AAP) with conformation change due to aptamer-protein binding [124]. The researchers engineered an AAP, sg8, which binds to CCRF-CEM lymphoblastic lymphoma cells. The sg8 aptamer is composed of three components: an aptamer sequence that binds to cancer cells (A-strand), a poly-T linker (B-strand), and a short DNA sequence (C-strand) complementary to a part of the A-strand, with a fluorophore and a quencher conjugated at either $5^{\prime}$ or $3^{\prime}$ terminus. In the absence of a target, the aptamer probe is free and its hairpin structure keeps the fluorophore near the quencher, without giving any fluorescence signal. However, once the probe binds to the membrane protein of the target cancer cell, its conformation is changed, leading to an activated fluorescence signal. Figure 5 shows the design and activation of AAP probe.

\subsection{Aptamer-Based Nanoimaging Agents for CT and MRI}

The advance of nanoimaging medicine relies heavily on the development of novel biocompatible organic and inorganic nanomaterials like block copolymers, liposomes, quantum dots (QDs), single-wall carbon nanotubes (SWCNTs), gold nanoparticles (GNPs), and magnetic nanoparticles [115,125-127]. All these nanomaterials have unique physical or chemical properties for diagnostic or therapeutic applications. Combining these nanomaterials with aptamers can result in unprecedented characteristics for in vivo optical imaging (e.g., with QDs) and photothermal therapy (e.g., with GNPs and SWCNTs).

Aptamer-nanomaterials probes have been used in Computed Tomography (CT) and Magnetic Resonance Imaging (MRI). CT and MRI are the most useful and popular imaging techniques for biomedicine. The Indium-111 ( ${ }^{111} \mathrm{In}$ ) labeled aptamer-hollow gold nanosphere (HAuNS) for head and neck cancer detection through CT scan was reported [126]. Epidermal growth factor receptor (EGFR) targeting aptamers were conjugated to HAuNS by attaching a thiol-terminated single-stranded DNA to the HAuNS to generate specific aptamer-HAuNS nanoparticles. In the xenograft tumor-bearing mouse model experiment, ${ }^{111}$ In-labeled aptamer-HAuNS nanoparticles showed greater cancer cell uptake efficiency than ${ }^{111}$ In labeled antibody-HAuNS nanoparticles did. Besides the head and neck cancer cell detection, an A10 aptamer probe and gold nanoparticle conjugate to target PSMA of prostate cancer cell was also reported for CT imaging.

For MRI-based molecular imaging, aptamers have been conjugated to paramagnetic materials such as iron oxide nanoparticles. The A10 aptamer has been labeled on the paramagnetic nanoparticle to target PSMA-expression prostate cancer cell with high sensitivity and specificity. Recently, the Haam group conjugated a vascular endothelial growth factor receptor 2 (VEGFR2) - Specific aptamer on magnetic nanocrystal surface for detection of the angiogenic vasculature of glioblastoma via magnetic resonance imaging. The in vivo mouse model test demonstrated aptamer-conjugated magnetic nanocrystal has excellent MRI sensitivity with no cytotoxicity [128]. 

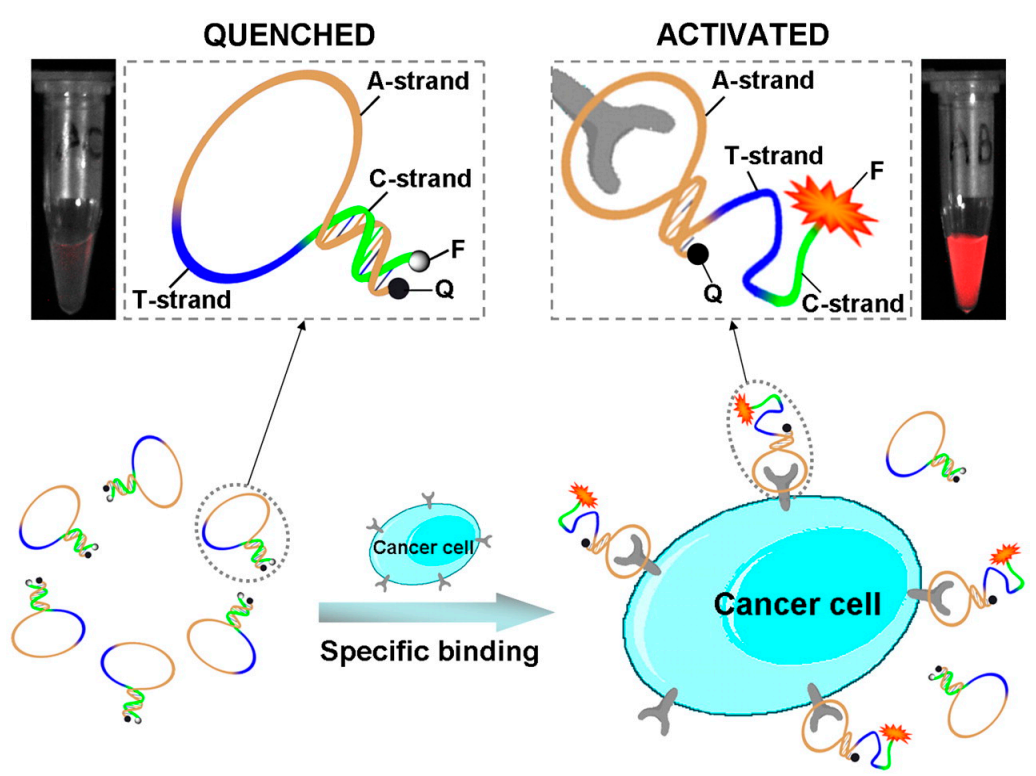

Figure 5. Schematic representation of the design of the activatable aptamers probe (AAP) [124].

\section{Aptamers as Vehicles for Drug Delivery}

\subsection{Aptamer-Polymer Hybrid Delivery System}

With great biocompatibility, the use of aptamer and synthetic copolymers are considered as attractive materials for clinical application. Langer group developed an aptamer-polymeric nanoparticle bioconjugate containing a poly (lactic acid)-block-polyethylene glycol copolymer with a terminal carboxylic acid functional group (PLA-PEG-COOH) and encapsulated rhodamine-labeled dextran within the nanoparticle [129]. The bioconjugated nanoparticles can efficiently target and enter prostate LNCaP epithelial cells that overexpress PSMA antigen protein within two hours. Using the same cancer model, they further generated docetaxel (Dtxl)-encapsulated nanoparticles formulated with poly (D, L-lactic-co-glycolic acid)-block-poly (ethylene glycol) (PLGA-b-PEG) copolymer and surface functionalized with the A10 aptamers that recognize the PSMA protein as well [121]. This Dtxl-encapsulated aptamer-nanoparticle showed significantly enhanced in vitro cellular toxicity for prostate cancer cells. Moreover, a single intratumoral injection of aptamer-nanoparticle bioconjugates resulted in a drastically reduced tumor burden. Five of seven mice treated with such bioconjugates showed complete tumor regression, whereas only two of seven mice showed regression in the group of non-aptamer targeted bioconjugates.

A similar aptamer-PLGA bioconjugate nanoparticle system was used to deliver paclitaxel for glioma treatment [130]. A DNA aptamer, AS1411, which specifically binds to nucleolin that was highly expressed in the plasma membrane of both cancer cells and endothelial cells in angiogenic blood vessels, was conjugated to the surface of PEG-PLGA nanoparticles. The bioconjugates showed significantly higher efficacy compared with the conventional paclitaxel drug in vivo, evidenced by reduced tumor size and increased animal survival rate. In summary, the aptamer-polymer conjugates have shown promise in clinical applications for drug delivery, as both PEG and PLGA have been well studied in many US Food and Drug Administration (FDA) approved formulations [131-133]. 


\subsection{Aptamer-Liposome Hybrid Delivery System}

Liposomes are significant pharmaceutical carriers for drug delivery. Being the most successful drug-delivery systems over the past thirty years, many liposome-based drugs have been approved by the US FDA to treat diseases and many more have been in clinical trials [134-136]. As aptamer-liposome bioconjugates, cholesterol-modified aptamers have become commercially available, attributed to the attractive property that aptamers can be spontaneously anchored on the outer shell during the conjugated nanoparticle formation [137]. This advantage has been utilized to engineer liposomes to deliver cisplatin and taxol. Cisplatin is a great chemotherapeutic agent to treat a broad range of tumors. Despite its excellent antitumor efficacy, cisplatin has major drawbacks of lacking cell specificity and severe adverse effects. The AS1411 aptamer-liposome bioconjugate system can effectively deliver cisplatin to specific cell targets to mitigate these negative effects. Using aptamer-liposome bioconjugates as carriers for cisplatin, the selectivity of cisplatin was greatly enhanced, as evidenced by effective killing of the target cancer cells but not the control cells [138]. Compared to non-targeting liposomes, the AS1411 aptamer-functionalized liposomes that contain taxol have increased cellular uptake rate and cytotoxicity for MCF-7 breast cancer cells. Athymic nude mice bearing xenograft MCF-7 tumors treated with intratumorally injected aptamer-functionalized liposomes exhibited an earlier onset of tumor inhibition and improved anticancer efficacy [139].

A bone tissue specific aptamer-functionalized liposome nanoparticle system for therapeutic siRNA delivery has been developed. Metabolic skeletal disorders associated with impaired bone formation presents a clinical challenge. RNA interference-based approaches aimed at promoting osteoblastic bone formation holds promise for a cure of this disease. Plekhol protein has been identified as an intracellular negative regulator of bone formation and Plekhol siRNA was shown to promote bone formation. An osteoblast-specific aptamer CH6 was selected by cell-SELEX and conjugated to liposome nanoparticles encapsulating osteogenic Plekhol siRNA. This aptamer-liposome can bind with osteoblast and specifically deliver siRNAs to facilitate bone formation for both osteopenic and healthy rodents [140].

\subsection{Aptamer-Dendrimer Hybrid Delivery System}

Dendrimers are a unique type of synthetic globular macromolecules, which consist of three parts from the interior to the surface: a central core, a repeated and hyperbranched mantle, and a high density of surface functionalities [141-143]. Unlike conventional polymer, they possess several favorable features for use in drug delivery, including well-defined molecular weight, confined nanoscale size, multivalency, monodispersity, ease of preparation and modification, high aqueous solubility and high drug-loading capacity [144-147]. Recently, the combination of conventional chemotherapy with immunotherapy (chemoimmunotherapy) has proven a novel and effective cancer treatment strategy, providing invaluable preclinical and clinical outcomes [148-150]. Jon and co-workers reported an aptamer-dendrimer bioconjugate based nano-delivery system for effective chemoimmunotherapy. A G4 polyamidoamine (PAMAM) as carrier, an RNA aptamer that specifically recognizes PSMA was used as a prostate cancer targeting moiety, Doxorubicin (Dox) was chosen as chemotherapeutic agent, and the unmethylated $\mathrm{CpG}$ duplex oligonucleotides (dONT) as an immuno-stimulant. The unique resulting aptamer-dendrimer bioconjugate allowed Dox to be loaded via an intercalating interaction between 
double stranded CG base pairs and was specially delivered to PSMA-overexpressed prostate cancer. Serum stability is also an essential prerequisite for drug-delivery vehicle development. Jon and co-workers also indicated enhanced stability of RNA aptamer in serum due to attachment to dendrimer. This is attributed to the steric hindrance generated around aptamer-dONTs attached to the dendrimer core, which prevented nucleases access to the cleavage site of the bioconjugate [147].

Besides the above mentioned studies, several aptamer-based bioconjugate systems including gold-nanostars [151], single-walled carbon nanotubes (CNT) [152,153], gold nanoparticle-hybridized graphene oxide (AuNP-GO) [154], superparamagnetic iron oxide nanoparticles (SPION) [155], quantum dots [102], and gold nanoparticles (GNPs) [156] for drug delivery, imaging or therapy have been reported. Although the results of studies have been promising so far, more in vivo evaluation and validation experiments are still required.

\section{Aptamers as Potential Drugs}

\subsection{Therapeutic Aptamers in Cancer Therapy}

In the clinic, aptamer-based therapeutics is gaining momentum, which can be used as conventional therapeutic drugs in the same way as monoclonal antibody. Macugen (pegaptanib), a selective vascular endothelial growth factor (VEGF) antagonist, was approved in 2004 by the US FDA for the treatment of neovascular (wet) age-related macular degeneration (AMD) [157-159]. Today, more candidates were in the pipeline undergoing clinical trials for disease treatment, ranging from cancer to infectious pathogens. Bruno [160], Byrne and Wower [161], and $\mathrm{Zu} \mathrm{[162],} \mathrm{have} \mathrm{recently} \mathrm{summarized} \mathrm{the}$ therapeutic aptamers which are in the clinical trials or in pharmaceutical development pipelines. The following section focuses on the potential therapeutic aptamers in the cancer immunotherapy field.

Programmed cell death-1 (PD-1; also known as CD279) [163,164] and cytotoxic T-lymphocyte-associated protein-4 (CTLA-4; also known as CD 152) [165-167] are negative regulators of T-cell activity and limit the activity of T-cells through interaction with their ligands. They act as brakes in the immune system, allowing cancer cells to escape it [168-170]. Blocking the immunoinhibitory pathways using monoclonal antibodies has led to provoke robust and durable antitumor responses. Anti-CTLA-4 (Ipilimumab; Yervoy) [171,172] and Anti-PD-1 (Nivolumab; Option and Pembrolizumab; Keytruda) monoclonal antibodies have been approved by the US FDA for melanoma (a type of skin cancer) treatment [172-174] and are been currently tested in various tumor types [175,176]. Since monoclonal antibody therapy inherently carries a number of disadvantages including the limitation of using protein-based biologicals might be restricted by their potential immunogenicity, which could elicit neutralizing antibodies in patients. In addition, antibodies are cell-based products, which require complex and costly manufacturing technologies [177-181]. Alternative aptamer-based immunomodulators have been isolated and tested. The first aptamer, Del 60, was developed to bind and block murine CTLA-4 on activated T cells [182]. The monovalent aptamer bound to its target in solution has an approximate $\mathrm{K}_{\mathrm{d}}$ of $33-60 \mathrm{nM}$ that is comparable with the bivalent antibody $\left(\mathrm{K}_{\mathrm{d}} \sim 133 \mathrm{nM}\right)$. Therefore, Del 60 is able to reverse CTLA-4-mediated inhibition of T-cell proliferation in vitro. The in vivo bioactivity of Del 60 aptamer can be significantly enhanced by generating the tetravalent derivative. Most important, the tetravalent Del 60 aptamer potentiates protective immunity in mice tumor model 
with comparable potency to CTLA-4 monoclonal antibody. The murine PD-1 aptamer, MP7, was also developed. This DNA aptamer was specifically bound to murine extracellular domain of PD-1 and interrupted the PD-1/PD-L1 interaction. The 5' end of MP7 aptamer was modified by high molecular weight polyethylene glycol (PEG) to reduce the filtration rate and extended half-life, and without losing the ability to block PD-1/PD-L1 interaction. In addition, the PEGylated MP7 retained the ability to suppress the growth of PD-L1 (+) colon tumor cells in vivo with the comparable potency to anti-PD-1 antibody. Notably, the PEGylated MP7 was not cytotoxic and could enhance tumor-specific T-cell response without induction of Toll-like receptor 9 (TLR-9)-mediated innate immune response [183]. An aptamer to the T-cell major costimulatory receptor, 4-1 BB, was also isolated. This protein was repressed on the activated CD8 (+) T-cells [184-187]. The agonistic 4-1 BB aptamer that functions as the natural ligand to initiate a positive signal transduction cascade to enhance the survival of the CD8 (+) T-cells and induce tumor regression [188].

\subsection{Thrombin Binding Aptamers}

Thrombin, a multifunctional serine protease, is a significant target for anticoagulation and cardiovascular diseases therapy [189]. It plays a key role in the coagulation cascade reaction, converting soluble fibrinogen into insoluble fibrin proteins [190] and also involving many other coagulation catalyzing reactions, including platelet activation [191-193]. Thrombin recognizes substrate via two electropositive surfaces (fibrinogen-binding site, exosite I; heparin-binding, exosite II) composed essentially of basic amino acid residues, which are located on the opposite side of the active site of thrombin $[194,195]$. The inhibition and regulation of thrombin activity in vivo are the major solution in prevention and treatment of blood clotting abnormalities. The first DNA thrombin aptamer was isolated by Toole and co-workers in 1992, named thrombin binding aptamer (TBA) and the most active strand was a 15-mer oligonucleotide with a $\mathrm{K}_{\mathrm{d}} \sim 100 \mathrm{nM}$ [113]. The structure of the TBA was determined to be a intramolecular G-quadruplex, which interacts with the fibrinogen-binding site [196-200]. More new aptamers with higher affinity were isolated that contained a duplex region in addition to the quadruplex [201]. Nucleotide analogues such as non-natural isoguanosine (isoG), 5-hydroxymethyl-2'-deoxyuridine (hmU) [202,203], Dansyl/Cyclodextrin moieties [204], unlocked nucleic acid (UNA) [205] were also introduced to enhance the TBA affinity and biological activity. The first in vivo TBA anticoagulant properties were evaluated on cynomolgus monkeys and sheep [206]. The rapid onset of action and short half-life ( $\mathrm{t}_{1 / 2} \sim 2 \mathrm{~min}$ ) in vivo suggest that the thrombin aptamer may be useful in anticoagulation with extracorporeal circuits and acute clinical settings like surgical interventions. It also showed the ability to inhibit clot-bound thrombin activity and platelet thrombus formation in an ex vivo whole artery angioplasty model. It also represented specific dose-dependent inhibition of thrombin-induced platelet aggregation ability in human platelet-rich plasma [207]. Currently, the pre-clinical study is being evaluated by Archemix Corporation in preparation for human clinical trials [208]. Nu172 is another potentially thrombin inhibitor candidate, which was isolated from SELEX process and subsequently truncated to 26 nucleic acids without further chemical modification. It is currently being prepared for evaluation in phase II clinical trials for anticoagulation in patients undergoing coronary artery bypass graft (CABG) surgery treatments by ARCA Biopharma [209]. 


\section{Aptamer-Based Programmable Hydrogels}

The clinical pharmacokinetic (PK) and pharmacodynamic (PD) efficacy of therapeutics is affected by many factors, including drug concentration at the site of action, pathological area regional $\mathrm{pH}$, therapeutics solubility and stability, cellular uptake efficiency, cell membrane permeability, bioavailability, and renal clearance rate [210,211]. In recent years, there has been an increasing effort in the development of environmental-responsive bionanomaterials to facilitate targeted drug delivery and release control, including $\mathrm{pH}$ [212], redox reaction [213], enzyme [214,215], small molecule [216,217], temperature [218,219], and light [220,221]. Many review articles summarized progress in this research field [222-225]. Hydrogel, which can be synthesized from a variety of biological based materials, including polypeptides [226,227], polysaccharides [228,229], oligonucleotides [230,231], is one of the most attractive materials. However, since most hydrogel is highly permeable, it causes rapid release of loaded therapeutics in the tissue $[232,233]$. Current solution mostly depends on the control of pore size or disassembly rate of the material. However, it is still challenging to utilize those mechanisms to release drugs with temporal and spatial control and specificity. Aptamer-functionalized hydrogels can be programmed to release various and multiple therapeutics when needed through specific nucleic acid recognition and complementary hybridization process. Wang and co-workers recently developed a nucleic acid-based affinity hydrogel system for controlled protein release. Two different nucleic acid aptamers and complementary sequences were used to control the release rate of vascular endothelial growth factor (VEGF) and platelet-derive growth factor BB (BB) [234-237] in vitro.

The aptamer-functionalized hydrogel has also been used for controlled cell capture and release. The programmable hydrogel contains a primary complementary sequence (CS), an aptamer sequence, and a secondary CS. Initially, the primary CS was conjugate to the hydrogel on a solid support surface. The aptamer was hybridized with the primary CS and can specifically bind with cells through polyvalent aptamer-protein interactions. When the secondary CS was applied to trigger the hydrogel, the aptamer dissociated from the primary CS and hybridizes with the secondary CS. Therefore, polyvalent interactions between the cells and the hydrogel were weakened, causing nondestructive detachment of the cells from the solid surface [237]. In addition, aptamer-functionalized hydrogel has also been used as an artificial extracellular matrix (ECM) for cell adhesion without affecting cell viability [238].

\section{Aptamers in Precision Cancer Medicine}

Conventional approaches of clinical practice are drug centered, with a strategy of finding generalities between patients so that they can be clustered or grouped together and treated similarly [239]. Precision medicine is a new approach to integrate multiparameters including molecular, clinical, environmental data, and health outcomes to enhance disease diagnosis and treatment in an iterative fashion [240,241]. The potential of precision medicine is that it will yield treatments that deliver significant effects based on molecular characteristics of patients, rather than just the organ of origin. Oncology is the frontier of precision medicine with significant emphasis on identification of tumor-associated biomarkers [242-246]. Proteins are the most useful forms of biomarkers giving information about the genotype and phenotype of a certain disease. The majority of protein-based biomarkers are found in blood and body fluids, and the discovery of such biomarkers is crucial in providing physicians with essential information to 
diagnose diseases and treat patients. However, a very limited number of validated biomarkers have been utilized in routine practice, such as human epidermal growth factor receptor 2 (HER2/neu) in breast cancer [247], prostate-specific antigen (PSA) in prostate cancer [248], carbohydrate antigen 125 (CA-125) in ovarian cancer [249], and K-Ras mutation in colorectal cancer or non-small-cell lung cancer (NSCLC) [250,251]. Moreover, biomarkers are often found at low-abundance, and therefore the detection method should be sensitive enough to distinguish between protein isoforms and molecular structure difference through post-translational modification [252,253]. If cancers are defined or classified by their molecular makeup, advanced molecular tests should be considered standard diagnostic tools for patients with cancer [239]. In addition, new technologies for rapid biomarker detection are needed. An enzyme linked oligonucleotide assay (ELONA) was first reported by Drolet and co-workers using aptamer-based sandwich assay to replace antibodies to detect human vascular endothelial growth factor (hVEGF) protein [254]. Recently, several groups have reported aptamer-based tumor marker discovery platforms with versatile development potential or multiplexing capabilities. Yang and co-workers have developed an aptamer-functionalized graphene oxide to detect platelet-derived growth factors (PDGF) [255]. Walker and co-workers have recently described a slow off-rate modified aptamer (SOMAmer) biomarker discovery platform that is capable of simultaneously measuring thousands of proteins from serum or plasma with small sample volume. By using this system, 58 potential chronic kidney disease (CKD) biomarkers were discovered [256]. They also utilized this platform to conduct a large scale study of NSCLC biomarkers screening from which 44 biomarkers were discriminated [257]. Aptamer-facilitated biomarker discovery (AptaBiD) technology was introduced to detect biomarkers differently-expressed from immature and mature dendritic cell membrane. Through multi-cycle selection, the biomarkers were isolated and subsequently analyzed by mass spectrometry. Tan and co-workers summarized the development of nucleic acid aptamers in the areas of cell membrane analysis, cell detection and isolation for biomarkers discovery [258]. Liu and co-workers summarized the recent research progress of aptamer-based biosensors for biomedical diagnostics [259] and Tang and co-workers reviewed the development of aptamer-based enzyme-linked immunosorbent assay (ELISA) for biomolecules detection field [260].

Novel technologies using aptamers continue to evolve in precision medicine, providing enormous opportunities for tumor related biomarker discovery and detection.

\section{Future Perspective and Conclusions}

SELEX and cell-SELEX are effective and versatile techniques to generate a large number of aptamer-based probes that can recognize specific molecular or cell targets even with limited or no information about the markers the aptamers will bind to. These aptamers contribute to biomedical research and practice in the areas of imaging, biomarker discovery, drug delivery, etc. Since the fundamental patent for SELEX has recently expired, an increasing number of aptamers and related applications are expected to be developed and more aptamer-based disease diagnostic and therapeutic molecules will be put in the pipeline for clinical development.

Although aptamer-based drug targeting and delivery systems have been proven highly specific to cancer cells, the following questions still need to be answered: (1) how aptamers of high affinity to the disease-associated targets can be more efficiently and rapidly selected; (2) how aptamers can be 
engineered to maintain their correct conformation and structure on the surface of nanoparticles or liposomes; (3) how the shape or size of the nanoparticles can affect the target binding ability of aptamers; and (4) how in vivo biostability of aptamers can be improved to be suitable for clinical use.

In summary, aptamers are highly attractive and promising tools for functional characterization of biomolecules, disease detection, therapeutic intervention as drug carriers, and the pharmaceutical lead compounds. Aptamers have significant translational potential to be an essential part of safe, controllable, and robust drug delivery systems. In many fields of biomedical research, aptamers have been playing key roles and will continue to open up new possibilities unconceivable today.

\section{Conflicts of Interest}

The authors declare no conflict of interest.

\section{References}

1. Ellington, A.D.; Szostak, J.W. In vitro selection of RNA molecules that bind specific ligands. Nature 1990, 346, 818-822.

2. Tuerk, C.; Gold, L. Systematic evolution of ligands by exponential enrichment: RNA ligands to bacteriophage t4 DNA polymerase. Science 1990, 249, 505-510.

3. Feigon, J.; Dieckmann, T.; Smith, F.W. Aptamer structures from a to $\zeta$. Chem. Biol. 1996, 3, 611-617.

4. Patel, D.J.; Suri, A.K.; Jiang, F.; Jiang, L.; Fan, P.; Kumar, R.A.; Nonin, S. Structure, recognition and adaptive binding in RNA aptamer complexes1. J. Mol. Biol. 1997, 272, 645-664.

5. Hermann, T.; Patel, D.J. Adaptive recognition by nucleic acid aptamers. Science 2000, 287, $820-825$.

6. Piganeau, N.; Schroeder, R. Aptamer structures: A preview into regulatory pathways? Chem. Biol. 2003, 10, 103-104.

7. Hendeles, L.; Weinberger, M. Theophylline a "state of the art" review. Pharmacother. J. Hum. Pharmacol. Drug Ther. 1983, 3, 2-44.

8. Jenison, R.; Gill, S.; Pardi, A.; Polisky, B. High-resolution molecular discrimination by RNA. Science 1994, 263, 1425-1429.

9. Geiger, A.; Burgstaller, P.; von der Eltz, H.; Roeder, A.; Famulok, M. RNA aptamers that bind L-arginine with sub-micromolar dissociation constants and high enantioselectivity. Nucleic Acids Res. 1996, 24, 1029-1036.

10. Argos, P.; Rossmann, M.G.; Grau, U.M.; Zuber, H.; Frank, G.; Tratschin, J.D. Thermal stability and protein structure. Biochemistry 1979, 18, 5698-5703.

11. Pontius, B.W.; Berg, P. Rapid renaturation of complementary DNA strands mediated by cationic detergents: A role for high-probability binding domains in enhancing the kinetics of molecular assembly processes. Proc. Natl. Acad. Sci. 1991, 88, 8237-8241.

12. SantaLucia, J.; Hicks, D. The thermodynamics of DNA structural motifs. Annu. Rev. Biophys. Biomol. Struct. 2004, 33, 415-440.

13. Chien, A.; Edgar, D.B.; Trela, J.M. Deoxyribonucleic acid polymerase from the extreme thermophile thermus aquaticus. J. Bacteriol. 1976, 127, 1550-1557. 
14. Brown, D.M.; Todd, A.R. 13. Nucleotides. Part x. Some observations on the structure and chemical behaviour of the nucleic acids. J. Chem. Soc. (Resumed) 1952, 52-58.

15. Beaucage, S.L.; Caruthers, M.H. Deoxynucleoside phosphoramidites-A new class of key intermediates for deoxypolynucleotide synthesis. Tetrahedron Lett. 1981, 22, 1859-1862.

16. Reese, C.B. Oligo- and poly-nucleotides: 50 years of chemical synthesis. Org. Biomol. Chem. 2005, 3, 3851-3868.

17. Kool, E.T. Preorganization of DNA: Design principles for improving nucleic acid recognition by synthetic oligonucleotides. Chem. Rev. 1997, 97, 1473-1488.

18. Ramzaeva, N.; Rosemeyer, H.; Leonard, P.; Mühlegger, K.; Bergmann, F.; von der Eltz, H.; Seela, F. Oligonucleotides functionalized by fluorescein and rhodamine dyes: Michael addition of methyl acrylate to 2'-deoxypseudouridine. Helv. Chim. Acta 2000, 83, 1108-1126.

19. Tung, C.-H.; Stein, S. Preparation and applications of peptide-oligonucleotide conjugates. Bioconjugate Chem. 2000, 11, 605-618.

20. Williams, B.A.R.; Chaput, J.C. Synthesis of peptide-oligonucleotide conjugates using a heterobifunctional crosslinker. In Current Protocols in Nucleic Acid Chemistry; John Wiley \& Sons, Inc.: Hoboken, NJ, USA, 2001.

21. Niemeyer, C.M. The developments of semisynthetic DNA-protein conjugates. Trends Biotechnol. 2002, 20, 395-401.

22. Ito, T.; Ueno, Y.; Komatsu, Y.; Matsuda, A. Synthesis, thermal stability and resistance to enzymatic hydrolysis of the oligonucleotides containing 5-(n-aminohexyl)carbamoyl-2'-o-methyluridines. Nucleic Acids Res. 2003, 31, 2514-2523.

23. Schoetzau, T.; Langner, J.; Moyroud, E.; Roehl, I.; Vonhoff, S.; Klussmann, S. Aminomodified nucleobases: Functionalized nucleoside triphosphates applicable for selex. Bioconjugate Chem. 2003, 14, 919-926.

24. Tennilä, T.; Antopolsky, M.; Azhayev, A.; Azhayeva, E. Peptide-oligonucleotide conjugates form stable and selective complexes with antibody and DNA. Bioconjugate Chem. 2008, 19, 1361-1367.

25. Kricka, L.J.; Fortina, P. Analytical ancestry: "Firsts" in fluorescent labeling of nucleosides, nucleotides, and nucleic acids. Clin. Chem. 2009, 55, 670-683.

26. Schena, M.; Shalon, D.; Davis, R.W.; Brown, P.O. Quantitative monitoring of gene expression patterns with a complementary DNA microarray. Science 1995, 270, 467-470.

27. Pirrung, M.C. How to make a DNA chip. Angew. Chem. Int. Ed. 2002, 41, 1276-1289.

28. Sassolas, A.; Leca-Bouvier, B.D.; Blum, L.J. DNA biosensors and microarrays. Chem. Rev. 2008, $108,109-139$.

29. Zhao, Y.; Hao, C.; Ma, W.; Yong, Q.; Yan, W.; Kuang, H.; Wang, L.; Xu, C. Magnetic bead-based multiplex DNA sequence detection of genetically modified organisms using quantum dot-encoded silicon dioxide nanoparticles. J. Phys. Chem. C 2011, 115, 20134-20140.

30. Famulok, M.; Blind, M.; Mayer, G. Intramers as promising new tools in functional proteomics. Chem. Biol. 2001, 8, 931-939.

31. Burke, D.H.; Nickens, D.G. Expressing RNA aptamers inside cells to reveal proteome and ribonome function. Brief. Funct. Genomics Proteomics 2002, 1, 169-188. 
32. Famulok, M.; Verma, S. In vivo-applied functional RNAs as tools in proteomics and genomics research. Trends Biotechnol. 2002, 20, 462-466.

33. Choi, K.H.; Park, M.W.; Lee, S.Y.; Jeon, M.-Y.; Kim, M.Y.; Lee, H.K.; Yu, J.; Kim, H.-J.; Han, K.; Lee, H.; et al. Intracellular expression of the t-cell factor-1 rna aptamer as an intramer. Mol. Cancer Ther. 2006, 5, 2428-2434.

34. Kwak, H.; Hwang, I.; Kim, J.H.; Kim, M.Y.; Yang, J.S.; Jeong, S. Modulation of transcription by the peroxisome proliferator-activated receptor $\delta$-binding RNA aptamer in colon cancer cells. Mol. Cancer Ther. 2009, 8, 2664-2673.

35. Zhang, C. Hybridoma technology for the generation of monoclonal antibodies. In Antibody Methods and Protocols; Proetzel, G., Ebersbach, H., Eds.; Humana Press: New York, NY, USA, 2012; Volume 901, pp. 117-135.

36. Qin, C.-F.; Li, G.-C. Mammalian cell display technology coupling with aid induced shm in vitro: An ideal approach to the production of therapeutic antibodies. Int. Immunopharmacol. 2014, 23, 380-386.

37. Sassanfar, M.; Szostak, J.W. An rna motif that binds ATP. Nature 1993, 364, 550-553.

38. Mannironi, C.; di Nardo, A.; Fruscoloni, P.; Tocchini-Valentini, G.P. In vitro selection of dopamine RNA ligands. Biochemistry 1997, 36, 9726-9734.

39. Morris, K.N.; Jensen, K.B.; Julin, C.M.; Weil, M.; Gold, L. High affinity ligands from in vitro selection: Complex targets. Proc. Natl. Acad. Sci. USA 1998, 95, 2902-2907.

40. Blank, M.; Weinschenk, T.; Priemer, M.; Schluesener, H. Systematic evolution of a DNA aptamer binding to rat brain tumor microvessels: Selective targeting of endothelial regulatory protein pigpen. J. Biol. Chem. 2001, 276, 16464-16468.

41. Daniels, D.A.; Chen, H.; Hicke, B.J.; Swiderek, K.M.; Gold, L. A tenascin-c aptamer identified by tumor cell selex: Systematic evolution of ligands by exponential enrichment. Proc. Natl. Acad. Sci. USA 2003, 100, 15416-15421.

42. Wang, C.; Zhang, M.; Yang, G.; Zhang, D.; Ding, H.; Wang, H.; Fan, M.; Shen, B.; Shao, N. Single-stranded DNA aptamers that bind differentiated but not parental cells: Subtractive systematic evolution of ligands by exponential enrichment. J. Biotechnol. 2003, 102, 15-22.

43. Mallikaratchy, P.; Stahelin, R.V.; Cao, Z.; Cho, W.; Tan, W. Selection of DNA ligands for protein kinase c-[small delta]. Chem. Commun. 2006, 3229-3231.

44. Tang, Z.; Shangguan, D.; Wang, K.; Shi, H.; Sefah, K.; Mallikratchy, P.; Chen, H.W.; Li, Y.; Tan, W. Selection of aptamers for molecular recognition and characterization of cancer cells. Anal. Chem. 2007, 79, 4900-4907.

45. Chen, H.W.; Medley, C.D.; Sefah, K.; Shangguan, D.; Tang, Z.; Meng, L.; Smith, J.E.; Tan, W. Molecular recognition of small-cell lung cancer cells using aptamers. ChemMedChem 2008, 3, 991-1001.

46. Sefah, K.; Tang, Z.W.; Shangguan, D.H.; Chen, H.; Lopez-Colon, D.; Li, Y.; Parekh, P.; Martin, J.; Meng, L.; Phillips, J.A.; et al. Molecular recognition of acute myeloid leukemia using aptamers. Leukemia 2009, 23, 235-244.

47. Tang, Z.; Parekh, P.; Turner, P.; Moyer, R.W.; Tan, W. Generating aptamers for recognition of virus-infected cells. Clin. Chem. 2009, 55, 813-822. 
48. Zhou, J.; Swiderski, P.; Li, H.; Zhang, J.; Neff, C.P.; Akkina, R.; Rossi, J.J. Selection, characterization and application of new RNA HIV GP 120 aptamers for facile delivery of dicer substrate sirnas into hiv infected cells. Nucleic Acids Res. 2009, 37, 3094-3109.

49. Mi, J.; Liu, Y.; Rabbani, Z.N.; Yang, Z.; Urban, J.H.; Sullenger, B.A.; Clary, B.M. In vivo selection of tumor-targeting RNA motifs. Nat. Chem. Biol. 2010, 6, 22-24.

50. Parekh, P.; Tang, Z.; Turner, P.C.; Moyer, R.W.; Tan, W. Aptamers recognizing glycosylated hemagglutinin expressed on the surface of vaccinia virus-infected cells. Anal. Chem. 2010, 82, 8642-8649.

51. Bayrac, A.T.; Sefah, K.; Parekh, P.; Bayrac, C.; Gulbakan, B.; Oktem, H.A.; Tan, W. In vitro selection of DNA aptamers to glioblastoma multiforme. ACS Chem. Neurosci. 2011, 2, 175-181.

52. Zhu, C.-L.; Lu, C.-H.; Song, X.-Y.; Yang, H.-H.; Wang, X.-R. Bioresponsive controlled release using mesoporous silica nanoparticles capped with aptamer-based molecular gate. J. Am. Chem. Soc. 2011, 133, 1278-1281.

53. He, X.; Zhao, Y.; He, D.; Wang, K.; Xu, F.; Tang, J. ATP-responsive controlled release system using aptamer-functionalized mesoporous silica nanoparticles. Langmuir 2012, 28, 12909-12915.

54. Wang, J.; Sefah, K.; Altman, M.B.; Chen, T.; You, M.; Zhao, Z.; Huang, C.Z.; Tan, W. Aptamer-conjugated nanorods for targeted photothermal therapy of prostate cancer stem cells. Chem.-Asian J. 2013, 8, 2417-2422.

55. Peng Ho, S.; Britton, D.H.O.; Stone, B.A.; Behrens, D.L.; Leffet, L.M.; Hobbs, F.W.; Miller, J.A.; Trainor, G.L. Potent antisense oligonucleotides to the human multidrug resistance-1 mRNA are rationally selected by mapping rna-accessible sites with oligonucleotide libraries. Nucleic Acids Res. 1996, 24, 1901-1907.

56. Li, M.; Lin, N.; Huang, Z.; Du, L.; Altier, C.; Fang, H.; Wang, B. Selecting aptamers for a glycoprotein through the incorporation of the boronic acid moiety. J. Am. Chem. Soc. 2008, 130, 12636-12638.

57. Mehedi Masud, M.; Kuwahara, M.; Ozaki, H.; Sawai, H. Sialyllactose-binding modified DNA aptamer bearing additional functionality by selex. Bioorg. Med. Chem. 2004, 12, 1111-1120.

58. Kusser, W. Chemically modified nucleic acid aptamers for in vitro selections: Evolving evolution. Rev. Mol. Biotechnol. 2000, 74, 27-38.

59. Keefe, A.D.; Cload, S.T. Selex with modified nucleotides. Curr. Opin. Chem. Biol. 2008, 12, 448-456.

60. Pagratis, N.C.; Bell, C.; Chang, Y.-F.; Jennings, S.; Fitzwater, T.; Jellinek, D.; Dang, C. Potent 2[prime]-amino-, and 2[prime]-fluoro-2[prime]- deoxyribonucleotide RNA inhibitors of keratinocyte growth factor. Nat. Biotechnol. 1997, 15, 68-73.

61. Kuwahara, M. Progress in chemically modified nucleic acid aptamers. In Chemical Biology of Nucleic Acids; Erdmann, V.A., Markiewicz, W.T., Barciszewski, J., Eds.; Springer Berlin Heidelberg: Berlin, Germany, 2014; pp. 243-270.

62. Kluszmann, S.; Nolte, A.; Bald, R.; Erdmann, V.A.; Furste, J.P. Mirror-image RNA that binds d-adenosine. Nat. Biotechnol. 1996, 14, 1112-1115.

63. Eulberg, D.; Klussmann, S. Spiegelmers: Biostable aptamers. ChemBioChem 2003, 4, 979-983.

64. Vater, A.; Klussmann, S. Turning mirror-image oligonucleotides into drugs: The evolution of spiegelmer ${ }^{\circledR}$ therapeutics. Drug Discov. Today 2015, 20, 147-155. 
65. Vallée-Bélisle, A.; Plaxco, K.W. Structure-switching biosensors: Inspired by nature. Curr. Opin. Struct. Biol. 2010, 20, 518-526.

66. Liu, J.; Stormo, G.D. Combining selex with quantitative assays to rapidly obtain accurate models of protein-DNA interactions. Nucleic Acids Res. 2005, 33, doi: 10.1093/nar/gni139.

67. Tombelli, S.; Minunni, M.; Luzi, E.; Mascini, M. Aptamer-based biosensors for the detection of HIV-1 Tat protein. Bioelectrochemistry 2005, 67, 135-141.

68. Eulberg, D.; Buchner, K.; Maasch, C.; Klussmann, S. Development of an automated in vitro selection protocol to obtain rna-based aptamers: Identification of a biostable substance $p$ antagonist. Nucleic Acids Res. 2005, 33, e45.

69. Gopinath, S. Methods developed for selex. Anal. Bioanal. Chem. 2007, 387, 171-182.

70. Li, S.; Xu, H.; Ding, H.; Huang, Y.; Cao, X.; Yang, G.; Li, J.; Xie, Z.; Meng, Y.; Li, X.; et al. Identification of an aptamer targeting hnRNP al by tissue slide-based selex. J. Pathol. 2009, 218 , $327-336$.

71. Gold, L.; Polisky, B.; Uhlenbeck, O.; Yarus, M. Diversity of oligonucleotide functions. Annu. Rev. Biochem. 1995, 64, 763-797.

72. Jayasena, S.D. Aptamers: An emerging class of molecules that rival antibodies in diagnostics. Clin. Chem. 1999, 45, 1628-1650.

73. Zhou, J.; Soontornworajit, B.; Snipes, M.P.; Wang, Y. Structural prediction and binding analysis of hybridized aptamers. J. Mol. Recognit. 2011, 24, 119-126.

74. Zuker, M. Mfold web server for nucleic acid folding and hybridization prediction. Nucleic Acids Res. 2003, 31, 3406-3415.

75. Shangguan, D.; Tang, Z.; Mallikaratchy, P.; Xiao, Z.; Tan, W. Optimization and modifications of aptamers selected from live cancer cell lines. ChemBioChem 2007, 8, 603-606.

76. Zhou, J.; Battig, M.; Wang, Y. Aptamer-based molecular recognition for biosensor development. Anal. Bioanal. Chem. 2010, 398, 2471-2480.

77. Rockey, W.M.; Hernandez, F.J.; Huang, S.-Y.; Cao, S.; Howell, C.A.; Thomas, G.S.; Liu, X.Y.; Lapteva, N.; Spencer, D.M.; McNamara, J.O.; et al. Rational truncation of an rna aptamer to prostate-specific membrane antigen using computational structural modeling. Nucleic Acid Ther. 2011, 21, 299-314.

78. Gupta, S.; Hirota, M.; Waugh, S.M.; Murakami, I.; Suzuki, T.; Muraguchi, M.; Shibamori, M.; Ishikawa, Y.; Jarvis, T.C.; Carter, J.D.; et al. Chemically modified DNA aptamers bind interleukin-6 with high affinity and inhibit signaling by blocking its interaction with interleukin-6 receptor. J. Biol. Chem. 2014, 289, 8706-8719.

79. Drory Retwitzer, M.; Polishchuk, M.; Churkin, E.; Kifer, I.; Yakhini, Z.; Barash, D. RNAPattMatch: A web server for RNA sequence/structure motif detection based on pattern matching with flexible gaps. Nucleic Acids Res. 2015, 43, doi: 10.1093/nar/gkv435.

80. Wang, K.; Gan, L.; Jiang, L.; Zhang, X.; Yang, X.; Chen, M.; Lan, X. Neutralization of staphylococcal enterotoxin b by an aptamer antagonist. Antimicrob. Agents Chemother. 2015, 59, 2072-2077.

81. Green, L.S.; Jellinek, D.; Jenison, R.; Östman, A.; Heldin, C.-H.; Janjic, N. Inhibitory DNA ligands to platelet-derived growth factor b-chain. Biochemistry 1996, 35, 14413-14424. 
82. Sayer, N.M.; Cubin, M.; Rhie, A.; Bullock, M.; Tahiri-Alaoui, A.; James, W. Structural determinants of conformationally selective, prion-binding aptamers. J. Biol. Chem. 2004, 279, 13102-13109.

83. Wang, P.; Hatcher, K.L.; Bartz, J.C.; Chen, S.G.; Skinner, P.; Richt, J.; Liu, H.; Sreevatsan, S. Selection and characterization of DNA aptamers against prpsc. Exp. Biol. Med. 2011, 236, 466-476.

84. Katilius, E.; Flores, C.; Woodbury, N.W. Exploring the sequence space of a DNA aptamer using microarrays. Nucleic Acids Res. 2007, 35, 7626-7635.

85. Cho, M.; Soo Oh, S.; Nie, J.; Stewart, R.; Eisenstein, M.; Chambers, J.; Marth, J.D.; Walker, F.; Thomson, J.A.; Soh, H.T. Quantitative selection and parallel characterization of aptamers. Proc. Natl. Acad. Sci. USA 2013, 110, 18460-18465.

86. Shigdar, S.; Qiao, L.; Zhou, S.-F.; Xiang, D.; Wang, T.; Li, Y.; Lim, L.Y.; Kong, L.; Li, L.; Duan, W. RNA aptamers targeting cancer stem cell marker cd133. Cancer Lett. 2013, 330, 84-95.

87. Yarden, Y.; Sliwkowski, M.X. Untangling the ErbB signalling network. Nat. Rev. Mol. Cell Biol. 2001, 2, 127-137.

88. Ciardiello, F.; Tortora, G. EGFR antagonists in cancer treatment. New Engl. J. Med. 2008, 358, $1160-1174$.

89. Mahlknecht, G.; Maron, R.; Mancini, M.; Schechter, B.; Sela, M.; Yarden, Y. Aptamer to ErbB-2/HER2 enhances degradation of the target and inhibits tumorigenic growth. Proc. Natl. Acad. Sci. USA 2013, 110, 8170-8175.

90. Chadd, H.E.; Chamow, S.M. Therapeutic antibody expression technology. Curr. Opin. Biotechnol. 2001, 12, 188-194.

91. Hudis, C.A. Trastuzumab-Mechanism of action and use in clinical practice. New Engl. J. Med. 2007, 357, 39-51.

92. Mallikaratchy, P.; Tang, Z.; Kwame, S.; Meng, L.; Shangguan, D.; Tan, W. Aptamer directly evolved from live cells recognizes membrane bound immunoglobin heavy mu chain in burkitt's lymphoma cells. Mol. Cell. Proteomics 2007, 6, 2230-2238.

93. Shangguan, D.; Cao, Z.; Meng, L.; Mallikaratchy, P.; Sefah, K.; Wang, H.; Li, Y.; Tan, W. Cell-specific aptamer probes for membrane protein elucidation in cancer cells. J. Proteome Res. 2008, 7, 2133-2139.

94. Van Simaeys, D.; Turek, D.; Champanhac, C.; Vaizer, J.; Sefah, K.; Zhen, J.; Sutphen, R.; Tan, W. Identification of cell membrane protein stress-induced phosphoprotein 1 as a potential ovarian cancer biomarker using aptamers selected by cell systematic evolution of ligands by exponential enrichment. Anal. Chem. 2014, 86, 4521-4527.

95. Tyagi, S.; Kramer, F.R. Molecular beacons: Probes that fluoresce upon hybridization. Nat. Biotechnol. 1996, 14, 303-308.

96. Li, J.J.; Fang, X.; Schuster, S.M.; Tan, W. Molecular beacons: A novel approach to detect protein-DNA interactions. Angew. Chem. Int. Ed. 2000, 39, 1049-1052.

97. Hamaguchi, N.; Ellington, A.; Stanton, M. Aptamer beacons for the direct detection of proteins. Anal. Biochem. 2001, 294, 126-131.

98. Li, J.J.; Fang, X.; Tan, W. Molecular aptamer beacons for real-time protein recognition. Biochem. Biophys. Res. Commun. 2002, 292, 31-40.

99. Nutiu, R.; Li, Y. Structure-switching signaling aptamers. J. Am. Chem. Soc. 2003, 125, 4771-4778. 
100. Wang, Y.-M.; Wu, Z.; Liu, S.-J.; Chu, X. Structure-switching aptamer triggering hybridization chain reaction on the cell surface for activatable theranostics. Anal. Chem. 2015, doi:10.1021/acs.analchem.5b01634.

101. Levy, M.; Cater, S.F.; Ellington, A.D. Quantum-dot aptamer beacons for the detection of proteins. ChemBioChem 2005, 6, 2163-2166.

102. Bagalkot, V.; Zhang, L.; Levy-Nissenbaum, E.; Jon, S.; Kantoff, P.W.; Langer, R.; Farokhzad, O.C. Quantum dot-aptamer conjugates for synchronous cancer imaging, therapy, and sensing of drug delivery based on bi-fluorescence resonance energy transfer. Nano Lett. 2007, 7, 3065-3070.

103. Zhou, D. Quantum dot-nucleic acid/aptamer bioconjugate-based fluorimetric biosensors. Biochem. Soc. Trans. 2012, 40, 635-639.

104. Wang, W.; Chen, C.; Qian, M.; Zhao, X.S. Aptamer biosensor for protein detection using gold nanoparticles. Anal. Biochem. 2008, 373, 213-219.

105. Song, K.-M.; Cho, M.; Jo, H.; Min, K.; Jeon, S.H.; Kim, T.; Han, M.S.; Ku, J.K.; Ban, C. Gold nanoparticle-based colorimetric detection of kanamycin using a DNA aptamer. Anal. Biochem. 2011, 415, 175-181.

106. Cheng, F.; He, Y.; Xing, X.-J.; Tan, D.-D.; Lin, Y.; Pang, D.-W.; Tang, H.-W. A gold nanoparticle-based label free colorimetric aptasensor for adenosine deaminase detection and inhibition assay. Analyst 2015, 140, 1572-1577.

107. Zhang, J.-Q.; Wang, Y.-S.; Xue, J.-H.; He, Y.; Yang, H.-X.; Liang, J.; Shi, L.-F.; Xiao, X.-L. A gold nanoparticles-modified aptamer beacon for urinary adenosine detection based on structureswitching/fluorescence-"turning on" mechanism. J. Pharm. Biomed. Anal. 2012, 70, 362-368.

108. Liu, J.; Bai, W.; Niu, S.; Zhu, C.; Yang, S.; Chen, A. Highly sensitive colorimetric detection of 17[bgr]-estradiol using split DNA aptamers immobilized on unmodified gold nanoparticles. Sci. Rep. 2014, 4.

109. Coons, A.H.; Creech, H.J.; Jones, R.N. Immunological properties of an antibody containing a fluorescent group. Exp. Biol. Med. 1941, 47, 200-202.

110. Engvall, E.; Perlmann, P. Enzyme-linked immunosorbent assay (elisa) quantitative assay of immunoglobulin g. Immunochemistry 1971, 8, 871-874.

111. Van Weemen, B.K.; Schuurs, A.H.W.M. Immunoassay using antigen-enzyme conjugates. FEBS Lett. 1971, 15, 232-236.

112. Ramos-Vara, J.A.; Miller, M.A. When tissue antigens and antibodies get along: Revisiting the technical aspects of immunohistochemistry-The red, brown, and blue technique. Vet. Pathol. Online 2014, 51, 42-87.

113. Bock, L.C.; Griffin, L.C.; Latham, J.A.; Vermaas, E.H.; Toole, J.J. Selection of single-stranded DNA molecules that bind and inhibit human thrombin. Nature 1992, 355, 564-566.

114. Dey, A.K.; Griffiths, C.; Lea, S.M.; James, W. Structural characterization of an anti-gp120 rna aptamer that neutralizes $\mathrm{r} 5$ strains of HIV-1. RNA 2005, 11, 873-884.

115. Wang, A.Z.; Bagalkot, V.; Vasilliou, C.C.; Gu, F.; Alexis, F.; Zhang, L.; Shaikh, M.; Yuet, K.; Cima, M.J.; Langer, R.; et al. Superparamagnetic iron oxide nanoparticle-aptamer bioconjugates for combined prostate cancer imaging and therapy. ChemMedChem 2008, 3, 1311-1315.

116. Zhang, J.; Jia, X.; Lv, X.-J.; Deng, Y.-L.; Xie, H.-Y. Fluorescent quantum dot-labeled aptamer bioprobes specifically targeting mouse liver cancer cells. Talanta 2010, 81, 505-509. 
117. Bernard, E.; Beking, M.; Rajamanickam, K.; Tsai, E.; DeRosa, M. Target binding improves relaxivity in aptamer-gadolinium conjugates. J. Biol. Inorg. Chem. 2012, 17, 1159-1175.

118. Li, F.; Dong, J.; Hu, X.; Gong, W.; Li, J.; Shen, J.; Tian, H.; Wang, J. A covalent approach for site-specific RNA labeling in mammalian cells. Angew. Chem. Int. Ed. 2015, 54, 4597-4602.

119. Charlton, J.; Sennello, J.; Smith, D. In vivo imaging of inflammation using an aptamer inhibitor of human neutrophil elastase. Chem. Biol. 1997, 4, 809-816.

120. Mi, J.; Zhang, X.; Giangrande, P.H.; McNamara Ii, J.O.; Nimjee, S.M.; Sarraf-Yazdi, S.; Sullenger, B.A.; Clary, B.M. Targeted inhibition of $\alpha v \beta 3$ integrin with an rna aptamer impairs endothelial cell growth and survival. Biochem. Biophys. Res. Commun. 2005, 338, 956-963.

121. Farokhzad, O.C.; Cheng, J.; Teply, B.A.; Sherifi, I.; Jon, S.; Kantoff, P.W.; Richie, J.P.; Langer, R. Targeted nanoparticle-aptamer bioconjugates for cancer chemotherapy in vivo. Proc. Natl. Acad. Sci. USA 2006, 103, 6315-6320.

122. Tang, L.; Yang, X.; Dobrucki, L.W.; Chaudhury, I.; Yin, Q.; Yao, C.; Lezmi, S.; Helferich, W.G.; Fan, T.M.; Cheng, J. Aptamer-functionalized, ultra-small, monodisperse silica nanoconjugates for targeted dual-modal imaging of lymph nodes with metastatic tumors. Angew. Chem. Int. Ed. 2012, 51, 12721-12726.

123. Lim, E.-K.; Kim, B.; Choi, Y.; Ro, Y.; Cho, E.-J.; Lee, J.H.; Ryu, S.-H.; Suh, J.-S.; Haam, S.; Huh, Y.-M. Aptamer-conjugated magnetic nanoparticles enable efficient targeted detection of integrin $\alpha \mathrm{v} \beta 3$ via magnetic resonance imaging. J. Biomed. Mater. Res. Part A 2014, 102, 49-59.

124. Shi, H.; He, X.; Wang, K.; Wu, X.; Ye, X.; Guo, Q.; Tan, W.; Qing, Z.; Yang, X.; Zhou, B. Activatable aptamer probe for contrast-enhanced in vivo cancer imaging based on cell membrane protein-triggered conformation alteration. Proc. Natl. Acad. Sci. USA 2011, 108, 3900-3905.

125. Zhang, C.; Ji, X.; Zhang, Y.; Zhou, G.; Ke, X.; Wang, H.; Tinnefeld, P.; He, Z. One-pot synthesized aptamer-functionalized CdTe: $\mathrm{Zn}^{2+}$ quantum dots for tumor-targeted fluorescence imaging in vitro and in vivo. Anal. Chem. 2013, 85, 5843-5849.

126. Melancon, M.P.; Zhou, M.; Zhang, R.; Xiong, C.; Allen, P.; Wen, X.; Huang, Q.; Wallace, M.; Myers, J.N.; Stafford, R.J.; et al. Selective uptake and imaging of aptamer- and antibody-conjugated hollow nanospheres targeted to epidermal growth factor receptors overexpressed in head and neck cancer. ACS Nano 2014, 8, 4530-4538.

127. Yan, L.A.; Shi, H.; He, X.; Wang, K.; Tang, J.; Chen, M.; Ye, X.; Xu, F.; Lei, Y. A versatile activatable fluorescence probing platform for cancer cells in vitro and in vivo based on self-assembled aptamer/carbon nanotube ensembles. Anal. Chem. 2014, 86, 9271-9277.

128. Kim, B.; Yang, J.; Hwang, M.; Choi, J.; Kim, H.-O.; Jang, E.; Lee, J.; Ryu, S.-H.; Suh, J.-S.; Huh, Y.-M.; et al. Aptamer-modified magnetic nanoprobe for molecular mr imaging of VEGFR2 on angiogenic vasculature. Nanoscale Res. Lett. 2013, 8, 399.

129. Farokhzad, O.C.; Jon, S.; Khademhosseini, A.; Tran, T.-N.T.; LaVan, D.A.; Langer, R. Nanoparticle-aptamer bioconjugates: A new approach for targeting prostate cancer cells. Cancer Res. 2004, 64, 7668-7672.

130. Guo, J.; Gao, X.; Su, L.; Xia, H.; Gu, G.; Pang, Z.; Jiang, X.; Yao, L.; Chen, J.; Chen, H. Aptamer-functionalized peg-plga nanoparticles for enhanced anti-glioma drug delivery. Biomaterials 2011, 32, 8010-8020. 
131. Lü, J.-M.; Wang, X.; Marin-Muller, C.; Wang, H.; Lin, P.H.; Yao, Q.; Chen, C. Current advances in research and clinical applications of plga-based nanotechnology. Expert Rev. Mol. Diagn. 2009, 9, 325-341.

132. Knop, K.; Hoogenboom, R.; Fischer, D.; Schubert, U.S. Poly(ethylene glycol) in drug delivery: Pros and cons as well as potential alternatives. Angew. Chem. Int. Ed. 2010, 49, 6288-6308.

133. Danhier, F.; Ansorena, E.; Silva, J.M.; Coco, R.; Le Breton, A.; Préat, V. Plga-based nanoparticles: An overview of biomedical applications. J. Control. Release 2012, 161, 505-522.

134. Kaneda, Y. Virosomes: Evolution of the liposome as a targeted drug delivery system. Adv. Drug Deliv. Rev. 2000, 43, 197-205.

135. Torchilin, V.P. Recent advances with liposomes as pharmaceutical carriers. Nat. Rev. Drug Discov. 2005, 4, 145-160.

136. Wagner, A.; Platzgummer, M.; Kreismayr, G.; Quendler, H.; Stiegler, G.; Ferko, B.; Vecera, G.; Vorauer-Uhl, K.; Katinger, H. Gmp production of liposomes-A new industrial approach. J. Liposome Res. 2006, 16, 311-319.

137. Xing, H.; Tang, L.; Yang, X.; Hwang, K.; Wang, W.; Yin, Q.; Wong, N.Y.; Dobrucki, L.W.; Yasui, N.; Katzenellenbogen, J.A.; et al. Selective delivery of an anticancer drug with aptamer-functionalized liposomes to breast cancer cells in vitro and in vivo. J. Mater. Chem. B 2013, 1, 5288-5297.

138. Cao, Z.; Tong, R.; Mishra, A.; Xu, W.; Wong, G.C.L.; Cheng, J.; Lu, Y. Reversible cell-specific drug delivery with aptamer-functionalized liposomes. Angew. Chem. Int. Ed. 2009, 48, 6494-6498.

139. Wu, J.; Song, C.; Jiang, C.; Shen, X.; Qiao, Q.; Hu, Y. Nucleolin targeting as 1411 modified protein nanoparticle for antitumor drugs delivery. Mol. Pharm. 2013, 10, 3555-3563.

140. Liang, C.; Guo, B.; Wu, H.; Shao, N.; Li, D.; Liu, J.; Dang, L.; Wang, C.; Li, H.; Li, S.; et al. Aptamer-functionalized lipid nanoparticles targeting osteoblasts as a novel RNA interference-based bone anabolic strategy. Nat. Med. 2015, 21, 288-294.

141. Tomalia, D.A.; Baker, H.; Dewald, J.; Hall, M.; Kallos, G.; Martin, S.; Roeck, J.; Ryder, J.; Smith, P. A new class of polymers: Starburst-dendritic macromolecules. Polym. J. 1985, 17, 117-132.

142. Tomalia, D.A. Birth of a new macromolecular architecture: Dendrimers as quantized building blocks for nanoscale synthetic polymer chemistry. Prog. Polym. Sci. 2005, 30, 294-324.

143. Yang, J.; Zhang, Q.; Chang, H.; Cheng, Y. Surface-engineered dendrimers in gene delivery. Chem. Rev. 2015, 115, 5274-5300.

144. Svenson, S.; Tomalia, D.A. Dendrimers in biomedical applications - Reflections on the field. Adv. Drug Deliv. Rev. 2005, 57, 2106-2129.

145. Zhou, J.; Soontornworajit, B.; Martin, J.; Sullenger, B.A.; Gilboa, E.; Wang, Y. A hybrid DNA aptamer-dendrimer nanomaterial for targeted cell labeling. Macromol. Biosci. 2009, 9, 831-835.

146. Zhou, J.; Soontornworajit, B.; Wang, Y. A temperature-responsive antibody-like nanostructure. Biomacromolecules 2010, 11, 2087-2093.

147. Lee, I.-H.; An, S.; Yu, M.K.; Kwon, H.-K.; Im, S.-H.; Jon, S. Targeted chemoimmunotherapy using drug-loaded aptamer-dendrimer bioconjugates. J. Control. Release 2011, 155, 435-441. 
148. Weihrauch, M.R.; Ansén, S.; Jurkiewicz, E.; Geisen, C.; Xia, Z.; Anderson, K.S.; Gracien, E.; Schmidt, M.; Wittig, B.; Diehl, V.; et al. Phase i/ii combined chemoimmunotherapy with carcinoembryonic antigen-derived HLA-a2-restricted cap-1 peptide and irinotecan, 5-fluorouracil, and leucovorin in patients with primary metastatic colorectal cancer. Clin. Cancer Res. 2005, 11, 5993-6001.

149. Najar, H.M.; Dutz, J.P. Topical cpg enhances the response of murine malignant melanoma to dacarbazine. J. Investig. Dermatol. 2008, 128, 2204-2210.

150. Millward, M.; Underhill, C.; Lobb, S.; McBurnie, J.; Meech, S.J.; Gomez-Navarro, J.; Marshall, M.A.; Huang, B.; Mather, C.B. Phase i study of tremelimumab (cp-675[thinsp]206) plus pf-3512676 (cpg 7909) in patients with melanoma or advanced solid tumours. Br. J. Cancer 2013, 108, 1998-2004.

151. Dam, D.H.M.; Lee, R.C.; Odom, T.W. Improved in vitro efficacy of gold nanoconstructs by increased loading of g-quadruplex aptamer. Nano Lett. 2014, 14, 2843-2848.

152. Mohammadi, M.; Salmasi, Z.; Hashemi, M.; Mosaffa, F.; Abnous, K.; Ramezani, M. Single-walled carbon nanotubes functionalized with aptamer and piperazine-polyethylenimine derivative for targeted sirna delivery into breast cancer cells. Int. J. Pharm. 2015, 485, 50-60.

153. Taghdisi, S.M.; Lavaee, P.; Ramezani, M.; Abnous, K. Reversible targeting and controlled release delivery of daunorubicin to cancer cells by aptamer-wrapped carbon nanotubes. Eur. J. Pharm. Biopharm. 2011, 77, 200-206.

154. Yang, L.; Tseng, Y.-T.; Suo, G.; Chen, L.; Yu, J.; Chiu, W.-J.; Huang, C.-C.; Lin, C.-H. Photothermal therapeutic response of cancer cells to aptamer-gold nanoparticle-hybridized graphene oxide under nir illumination. ACS Appl. Mater. Interfaces 2015, 7, 5097-5106.

155. Yu, M.K.; Kim, D.; Lee, I.-H.; So, J.-S.; Jeong, Y.Y.; Jon, S. Image-guided prostate cancer therapy using aptamer-functionalized thermally cross-linked superparamagnetic iron oxide nanoparticles. Small 2011, 7, 2241-2249.

156. Chen, W.-H.; Xu, X.-D.; Jia, H.-Z.; Lei, Q.; Luo, G.-F.; Cheng, S.-X.; Zhuo, R.-X.; Zhang, X.-Z. Therapeutic nanomedicine based on dual-intelligent functionalized gold nanoparticles for cancer imaging and therapy in vivo. Biomaterials 2013, 34, 8798-8807.

157. Gragoudas, E.S.; Adamis, A.P.; Cunningham, E.T.; Feinsod, M.; Guyer, D.R. Pegaptanib for neovascular age-related macular degeneration. New Engl. J. Med. 2004, 351, 2805-2816.

158. Takeda, A.L.; Colquitt, J.; Clegg, A.J.; Jones, J. Pegaptanib and ranibizumab for neovascular age-related macular degeneration: A systematic review. Br. J. Ophthalmol. 2007, 91, 1177-1182.

159. Novack, G.D. Pharmacotherapy for the treatment of choroidal neovascularization due to age-related macular degeneration. Annu. Rev. Pharmacol. Toxicol. 2008, 48, 61-78.

160. Bruno, J. Predicting the uncertain future of aptamer-based diagnostics and therapeutics. Molecules 2015, 20, 6866-6887.

161. Sundaram, P.; Kurniawan, H.; Byrne, M.E.; Wower, J. Therapeutic RNA aptamers in clinical trials. Eur. J. Pharm. Sci. 2013, 48, 259-271.

162. Sun, H.; Zhu, X.; Lu, P.Y.; Rosato, R.R.; Tan, W.; Zu, Y. Oligonucleotide aptamers: New tools for targeted cancer therapy. Mol. Ther. Nucleic Acids 2014, 3, e182. 
163. Butte, M.J.; Keir, M.E.; Phamduy, T.B.; Sharpe, A.H.; Freeman, G.J. Programmed death-1 ligand 1 interacts specifically with the b7-1 costimulatory molecule to inhibit t cell responses. Immunity 2007, 27, 111-122.

164. Keir, M.E.; Butte, M.J.; Freeman, G.J.; Sharpe, A.H. Pd-1 and its ligands in tolerance and immunity. Annu. Rev. Immunol. 2008, 26, 677-704.

165. Walunas, T.L.; Lenschow, D.J.; Bakker, C.Y.; Linsley, P.S.; Freeman, G.J.; Green, J.M.; Thompson, C.B.; Bluestone, J.A. Ctla-4 can function as a negative regulator of $\mathrm{t}$ cell activation. Immunity 1994, 1, 405-413.

166. Krummel, M.F.; Allison, J.P. Cd28 and ctla-4 have opposing effects on the response of t cells to stimulation. J. Exp. Med. 1995, 182, 459-465.

167. Alegre, M.-L.; Frauwirth, K.A.; Thompson, C.B. T-cell regulation by cd28 and ctla-4. Nat. Rev. Immunol. 2001, 1, 220-228.

168. Wilcox, R.A.; Feldman, A.L.; Wada, D.A.; Yang, Z.-Z.; Comfere, N.I.; Dong, H.; Kwon, E.D.; Novak, A.J.; Markovic, S.N.; Pittelkow, M.R.; et al. B7-h1 (pd-11, cd274) Suppresses Host Immunity in T-cell Lymphoproliferative Disorders. Blood 2009, 114, 2149-2158.

169. Steidl, C.; Shah, S.P.; Woolcock, B.W.; Rui, L.; Kawahara, M.; Farinha, P.; Johnson, N.A.; Zhao, Y.; Telenius, A.; Neriah, S.B.; et al. Mhc class ii transactivator ciita is a recurrent gene fusion partner in lymphoid cancers. Nature 2011, 471, 377-381.

170. Green, M.R.; Rodig, S.; Juszczynski, P.; Ouyang, J.; Sinha, P.; O’Donnell, E.; Neuberg, D.; Shipp, M.A. Constitutive ap-1 activity and ebv infection induce pd-11 in hodgkin lymphomas and posttransplant lymphoproliferative disorders: Implications for targeted therapy. Clin. Cancer Res. 2012, 18, 1611-1618.

171. O’Day, S.J.; Hamid, O.; Urba, W.J. Targeting cytotoxic t-lymphocyte antigen-4 (ctla-4). Cancer 2007, 110, 2614-2627.

172. Robert, C.; Ghiringhelli, F. What is the role of cytotoxic t lymphocyte-associated antigen 4 blockade in patients with metastatic melanoma? Oncologist 2009, 14, 848-861.

173. Hamid, O.; Robert, C.; Daud, A.; Hodi, F.S.; Hwu, W.-J.; Kefford, R.; Wolchok, J.D.; Hersey, P.; Joseph, R.W.; Weber, J.S.; et al. Safety and tumor responses with lambrolizumab (anti-pd-1) in melanoma. New Engl. J. Med. 2013, 369, 134-144.

174. Johnson, D.B.; Peng, C.; Sosman, J.A. Nivolumab in melanoma: Latest evidence and clinical potential. Ther. Adv. Med. Oncol. 2015, 7, 97-106.

175. Bracarda, S.; Altavilla, A.; Hamzaj, A.; Sisani, M.; Marrocolo, F.; del Buono, S.; Danielli, R. Immunologic checkpoints blockade in renal cell, prostate, and urothelial malignancies. Semin. Oncol. 2015, 42, 495-505.

176. Sundar, R.; Cho, B.-C.; Brahmer, J.R.; Soo, R.A. Nivolumab in nsclc: Latest evidence and clinical potential. Ther. Adv. Med. Oncol. 2015, 7, 85-96.

177. Chames, P.; Van Regenmortel, M.; Weiss, E.; Baty, D. Therapeutic antibodies: Successes, limitations and hopes for the future. Br. J. Pharmacol. 2009, 157, 220-233.

178. Harding, F.A.; Stickler, M.M.; Razo, J.; DuBridge, R.B. The immunogenicity of humanized and fully human antibodies: Residual immunogenicity resides in the CDR regions. $m A b s$ 2010, 2 , 256-265. 
179. Nelson, A.L.; Dhimolea, E.; Reichert, J.M. Development trends for human monoclonal antibody therapeutics. Nat. Rev. Drug Discov. 2010, 9, 767-774.

180. Sherbenou, D.W.; Behrens, C.R.; Su, Y.; Wolf, J.L.; Martin Iii, T.G.; Liu, B. The development of potential antibody-based therapies for myeloma. Blood Rev. 2015, 29, 81-91.

181. Wilkinson, T.C.I.; Gardener, M.J.; Williams, W.A. Discovery of functional antibodies targeting ion channels. J. Biomol. Screen. 2015, 20, 454-467.

182. Santulli-Marotto, S.; Nair, S.K.; Rusconi, C.; Sullenger, B.; Gilboa, E. Multivalent rna aptamers that inhibit ctla-4 and enhance tumor immunity. Cancer Res. 2003, 63, 7483-7489.

183. Prodeus, A.; Abdul-Wahid, A.; Fischer, N.W.; Huang, E.H.B.; Cydzik, M.; Gariepy, J. Targeting the pd-1/pd-11 immune evasion axis with DNA aptamers as a novel therapeutic strategy for the treatment of disseminated cancers. Mol. Ther. Nucleic Acids 2015, 4, e237.

184. Vinay, D.S.; Kwon, B.S. Role of $4-1 b b$ in immune responses. Semin. Immunol. 1998, 10, 481-489.

185. Sica, G.; Chen, L. Modulation of the immune response through 4-1bb. In Cancer Gene Therapy, Habib, N., Ed.; Springer US: New York, NY, USA, 2002; Volume 465, pp. 355-362.

186. Croft, M. Co-stimulatory members of the tnfr family: Keys to effective t-cell immunity? Nat. Rev. Immunol. 2003, 3, 609-620.

187. Watts, T.H. TNF/TNFR family members in costimulation of t cell responses. Annu. Rev. Immunol. 2005, 23, 23-68.

188. McNamara, J.O.; Kolonias, D.; Pastor, F.; Mittler, R.S.; Chen, L.; Giangrande, P.H.; Sullenger, B.; Gilboa, E. Multivalent 4-1bb binding aptamers costimulate cd $8(+) t$ cells and inhibit tumor growth in mice. J. Clin. Investig. 2008, 118, 376-386.

189. Di Cera, E. Thrombin as procoagulant and anticoagulant. J. Thromb. Haemost. 2007, 5, 196-202.

190. Mann, K.G. Biochemistry and physiology of blood coagulation. Thromb. Haemost. 1999, 82, $165-174$.

191. Di Cera, E. Thrombin. Mol. Aspects Med. 2008, 29, 203-254.

192. Eriksson, B.I.; Quinlan, D.J.; Eikelboom, J.W. Novel oral factor Xa and thrombin inhibitors in the management of thromboembolism. Annu. Rev. Med. 2011, 62, 41-57.

193. Depta, J.P.; Bhatt, D.L. New approaches to inhibiting platelets and coagulation. Annu. Rev. Pharmacol. Toxicol. 2015, 55, 373-397.

194. Stubbs, M.T.; Bode, W. The clot thickens: Clues provided by thrombin structure. Trends Biochem. Sci. 1995, 20, 23-28.

195. Davie, E.W.; Kulman, J.D. An overview of the structure and function of thrombin. Semin. Thromb. Hemost. 2006, 32, 003-015.

196. Macaya, R.F.; Schultze, P.; Smith, F.W.; Roe, J.A.; Feigon, J. Thrombin-binding DNA aptamer forms a unimolecular quadruplex structure in solution. Proc. Natl. Acad. Sci. 1993, 90, 3745-3749.

197. Wang, K.Y.; Krawczyk, S.H.; Bischofberger, N.; Swaminathan, S.; Bolton, P.H. The tertiary structure of a DNA aptamer which binds to and inhibits thrombin determines activity. Biochemistry 1993, 32, 11285-11292. 
198. Wang, K.Y.; McCurdy, S.; Shea, R.G.; Swaminathan, S.; Bolton, P.H. A DNA aptamer which binds to and inhibits thrombin exhibits a new structural motif for DNA. Biochemistry 1993, 32, 1899-1904.

199. Russo Krauss, I.; Merlino, A.; Randazzo, A.; Novellino, E.; Mazzarella, L.; Sica, F. High-resolution structures of two complexes between thrombin and thrombin-binding aptamer shed light on the role of cations in the aptamer inhibitory activity. Nucleic Acids Res. 2012, 40, 8119-8128.

200. Zhao, X.; Liu, B.; Yan, J.; Yuan, Y.; An, L.; Guan, Y. Structure variations of tba g-quadruplex induced by 2'-o-methyl nucleotide in $\mathrm{K}^{+}$and $\mathrm{Ca}^{2+}$ environments. Acta Biochim. Biophys. Sin. 2014, 46, 837-850.

201. Macaya, R.F.; Waldron, J.A.; Beutel, B.A.; Gao, H.; Joesten, M.E.; Yang, M.; Patel, R.; Bertelsen, A.H.; Cook, A.F. Structural and functional characterization of potent antithrombotic oligonucleotides possessing both quadruplex and duplex motifs. Biochemistry 1995, 34, 4478-4492.

202. Nallagatla, S.R.; Heuberger, B.; Haque, A.; Switzer, C. Combinatorial synthesis of thrombin-binding aptamers containing iso-guanine. J. Comb. Chem. 2009, 11, 364-369.

203. Virgilio, A.; Petraccone, L.; Scuotto, M.; Vellecco, V.; Bucci, M.; Mayol, L.; Varra, M.; Esposito, V.; Galeone, A. 5-hydroxymethyl-2'-deoxyuridine residues in the thrombin binding aptamer: Investigating anticoagulant activity by making a tiny chemical modification. ChemBioChem 2014, 15, 2427-2434.

204. De Tito, S.; Morvan, F.; Meyer, A.; Vasseur, J.-J.; Cummaro, A.; Petraccone, L.; Pagano, B.; Novellino, E.; Randazzo, A.; Giancola, C.; et al. Fluorescence enhancement upon g-quadruplex folding: Synthesis, structure, and biophysical characterization of a dansyl/cyclodextrin-tagged thrombin binding aptamer. Bioconjugate Chem. 2013, 24, 1917-1927.

205. Pasternak, A.; Hernandez, F.J.; Rasmussen, L.M.; Vester, B.; Wengel, J. Improved thrombin binding aptamer by incorporation of a single unlocked nucleic acid monomer. Nucleic Acids Res. 2011, 39, 1155-1164.

206. Griffin, L.; Tidmarsh, G.; Bock, L.; Toole, J.; Leung, L. In vivo Anticoagulant Properties of a Novel Nucleotide-Based Thrombin Inhibitor and Demonstration of Regional Anticoagulation in Extracorporeal Circuits. Blood 1993, 81, 3271-3276.

207. Li, W.; Kaplan, A.; Grant, G.; Toole, J.; Leung, L. A Novel Nucleotide-Based Thrombin Inhibitor Inhibits Clot-Bound Thrombin and Reduces Arterial Platelet Thrombus Formation. Blood 1994, $83,677-682$.

208. Nimjee, S.M.; Rusconi, C.P.; Sullenger, B.A. Aptamers: An emerging class of therapeutics. Annu. Rev. Med. 2004, 56, 555-583.

209. Ni, X.; Castanares, M.; Mukherjee, A.; Lupold, S.E. Nucleic acid aptamers: Clinical applications and promising new horizons. Curr. Med. Chem. 2011, 18, 4206-4214.

210. Vlieghe, P.; Lisowski, V.; Martinez, J.; Khrestchatisky, M. Synthetic therapeutic peptides: Science and market. Drug Discov. Today 2010, 15, 40-56.

211. Deitchman, A.N.; Derendorf, H. Measuring drug distribution in the critically ill patient. Adv. Drug Deliv. Rev. 2014, 77, 22-26. 
212. Yang, K.-N.; Zhang, C.-Q.; Wang, W.; Wang, P.C.; Zhou, J.-P.; Liang, X.-J. Ph-responsive mesoporous silica nanoparticles employed in controlled drug delivery systems for cancer treatment. Cancer Biol. Med. 2014, 11, 34-43.

213. Belbekhouche, S.; Reinicke, S.; Espeel, P.; Du Prez, F.E.; Eloy, P.; Dupont-Gillain, C.; Jonas, A.M.; Demoustier-Champagne, S.; Glinel, K. Polythiolactone-based redox-responsive layers for the reversible release of functional molecules. ACS Appl. Mater. Interfaces 2014, 6, 22457-22466.

214. Agostini, A.; Mondragón, L.; Pascual, L.; Aznar, E.; Coll, C.; Martínez-Máñez, R.; Sancenón, F.; Soto, J.; Marcos, M.D.; Amorós, P.; et al. Design of enzyme-mediated controlled release systems based on silica mesoporous supports capped with ester-glycol groups. Langmuir 2012, 28, 14766-14776.

215. Zhu, L.; Wang, T.; Perche, F.; Taigind, A.; Torchilin, V.P. Enhanced anticancer activity of nanopreparation containing an mmp2-sensitive peg-drug conjugate and cell-penetrating moiety. Proc. Natl. Acad. Sci. USA 2013, 110, 17047-17052.

216. Roy, D.; Sumerlin, B.S. Glucose-sensitivity of boronic acid block copolymers at physiological $\mathrm{pH}$. ACS Macro Lett. 2012, 1, 529-532.

217. Sinha, A.; Chakraborty, A.; Jana, N.R. Dextran-gated, multifunctional mesoporous nanoparticle for glucose-responsive and targeted drug delivery. ACS Appl. Mater. Interfaces 2014, 6, 22183-22191.

218. Roy, D.; Cambre, J.N.; Sumerlin, B.S. Triply-responsive boronic acidblock copolymers: Solution self-assembly induced by changes in temperature, $\mathrm{pH}$, or sugar concentration. Chem. Commun. 2009, 2106-2108.

219. Guo, Y.; Zhao, Y.; Zhao, J.; Han, M.; Zhang, A.; Wang, X. Codendrimer from polyamidoamine (pamam) and oligoethylene dendron as a thermosensitive drug carrier. Bioconjugate Chem. 2014, $25,24-31$.

220. Du, J.-Z.; Long, H.-Y.; Yuan, Y.-Y.; Song, M.-M.; Chen, L.; Bi, H.; Wang, J. Micelle-to-vesicle morphological transition via light-induced rapid hydrophilic arm detachment from a star polymer. Chem. Commun. 2012, 48, 1257-1259.

221. Yan, H.; Teh, C.; Sreejith, S.; Zhu, L.; Kwok, A.; Fang, W.; Ma, X.; Nguyen, K.T.; Korzh, V.; Zhao, Y. Functional mesoporous silica nanoparticles for photothermal-controlled drug delivery in vivo. Angew. Chem. Int. Ed. 2012, 51, 8373-8377.

222. Mura, S.; Nicolas, J.; Couvreur, P. Stimuli-responsive nanocarriers for drug delivery. Nat. Mater. 2013, 12, 991-1003.

223. Nakayama, M.; Akimoto, J.; Okano, T. Polymeric micelles with stimuli-triggering systems for advanced cancer drug targeting. J. Drug Target. 2014, 22, 584-599.

224. Crucho, C.I.C. Stimuli-responsive polymeric nanoparticles for nanomedicine. ChemMedChem 2015, 10, 24-38.

225. Shen, Y.; Fu, X.; Fu, W.; Li, Z. Biodegradable stimuli-responsive polypeptide materials prepared by ring opening polymerization. Chem. Soc. Rev. 2015, 44, 612-622. 
226. Altunbas, A.; Pochan, D. Peptide-based and polypeptide-based hydrogels for drug delivery and tissue engineering. In Peptide-Based Materials; Deming, T., Ed.; Springer Berlin Heidelberg: Berlin, Germany, 2012; Volume 310, pp. 135-167.

227. Cui, H.; Zhuang, X.; He, C.; Wei, Y.; Chen, X. High performance and reversible ionic polypeptide hydrogel based on charge-driven assembly for biomedical applications. Acta Biomater. 2015, 11, $183-190$.

228. Xu, X.; Jha, A.K.; Harrington, D.A.; Farach-Carson, M.C.; Jia, X. Hyaluronic acid-based hydrogels: From a natural polysaccharide to complex networks. Soft Matter 2012, 8, 3280-3294.

229. Yang, X.; Bakaic, E.; Hoare, T.; Cranston, E.D. Injectable polysaccharide hydrogels reinforced with cellulose nanocrystals: Morphology, rheology, degradation, and cytotoxicity. Biomacromolecules 2013, 14, 4447-4455.

230. Liu, X.; Li, T.; Liu, D.; Wang, Z. Fabricating three-dimensional hydrogel oligonucleotide microarrays to detect single nucleotide polymorphisms. Anal. Methods 2013, 5, 285-290.

231. Jung, Y.K.; Kim, J.; Mathies, R.A. Microfluidic linear hydrogel array for multiplexed single nucleotide polymorphism (SNP) detection. Anal. Chem. 2015, 87, 3165-3170.

232. Lin, C.-C.; Anseth, K. Peg hydrogels for the controlled release of biomolecules in regenerative medicine. Pharm. Res. 2009, 26, 631-643.

233. Hoare, T.R.; Kohane, D.S. Hydrogels in drug delivery: Progress and challenges. Polymer 2008, 49, 1993-2007.

234. Soontornworajit, B.; Zhou, J.; Shaw, M.T.; Fan, T.-H.; Wang, Y. Hydrogel functionalization with DNA aptamers for sustained pdgf-bb release. Chem. Commun. 2010, 46, 1857-1859.

235. Soontornworajit, B.; Zhou, J.; Wang, Y. A hybrid particle-hydrogel composite for oligonucleotide-mediated pulsatile protein release. Soft Matter 2010, 6, 4255-4261.

236. Soontornworajit, B.; Zhou, J.; Snipes, M.P.; Battig, M.R.; Wang, Y. Affinity hydrogels for controlled protein release using nucleic acid aptamers and complementary oligonucleotides. Biomaterials 2011, 32, 6839-6849.

237. Zhang, Z.; Chen, N.; Li, S.; Battig, M.R.; Wang, Y. Programmable hydrogels for controlled cell catch and release using hybridized aptamers and complementary sequences. J. Am. Chem. Soc. 2012, 134, 15716-15719.

238. Chen, N.; Zhang, Z.; Soontornworajit, B.; Zhou, J.; Wang, Y. Cell adhesion on an artificial extracellular matrix using aptamer-functionalized peg hydrogels. Biomaterials 2012, 33, 1353-1362.

239. Kurzrock, R.; Giles, F.J. Precision oncology for patients with advanced cancer: The challenges of malignant snowflakes. Cell Cycle 2015, in press.

240. Desmond-Hellmann, S. Toward Precision Medicine: A New Social Contract? Sci. Transl. Med. 2012, 4, doi:10.1126/scitranslmed.3003473.

241. Ashley, E.A. The precision medicine initiative: A new national effort. JAMA 2015, 313, 2119-2120. 
242. Iacobuzio-Donahue, C.A.; Maitra, A.; Shen-Ong, G.L.; van Heek, T.; Ashfaq, R.; Meyer, R.; Walter, K.; Berg, K.; Hollingsworth, M.A.; Cameron, J.L.; et al. Discovery of novel tumor markers of pancreatic cancer using global gene expression technology. Am. J. Pathol. 2002, 160, 1239-1249.

243. Yin, P.; Xu, G. Metabolomics for tumor marker discovery and identification based on chromatography-mass spectrometry. Expert Rev. Mol. Diagn. 2013, 13, 339-348.

244. Wu, J.-Y.; Cheng, C.-C.; Wang, J.-Y.; Wu, D.-C.; Hsieh, J.-S.; Lee, S.-C.; Wang, W.-M. Discovery of tumor markers for gastric cancer by proteomics. PLOS ONE 2014, 9, doi:10.1371/ journal.pone.0084158

245. Huang, H.-L.; Wu, Y.-C.; Su, L.-J.; Huang, Y.-J.; Charoenkwan, P.; Chen, W.-L.; Lee, H.-C.; Chu, W.C.-C.; Ho, S.-Y. Discovery of prognostic biomarkers for predicting lung cancer metastasis using microarray and survival data. BMC Bioinform. 2015, 16, 54.

246. Duffy, M.J.; Sturgeon, C.M.; Sölétormos, G.; Barak, V.; Molina, R.; Hayes, D.F.; Diamandis, E.P.; Bossuyt, P.M.M. Validation of new cancer biomarkers: A position statement from the european group on tumor markers. Clin. Chem. 2015, 61, 809-820.

247. Mitri, Z.; Constantine, T.; O'Regan, R. The HER2 receptor in breast cancer: Pathophysiology, clinical use, and new advances in therapy. Chemother. Res. Pract. 2012, 2012, 743193.

248. Gomella, L.G.; Liu, X.S.; Trabulsi, E.J.; Kelly, W.K.; Myers, R.; Showalter, T.; Dicker, A.; Wender, R. Screening for prostate cancer: The current evidence and guidelines controversy. Can. J. Urol. 2011, 18, 5875-5883.

249. Bast, R.C.; Badgwell, D.; Lu, Z.; Marquez, R.; Rosen, D.; Liu, J.; Baggerly, K.A.; Atkinson, E.N.; Skates, S.; Zhang, Z.; et al. New tumor markers: CA125 and beyond. Int. J. Gynecol. Cancer 2005, 15, 274-281.

250. Roberts, P.J.; Stinchcombe, T.E.; Der, C.J.; Socinski, M.A. Personalized medicine in non-small-cell lung cancer: Is K-Ras a useful marker in selecting patients for epidermal growth factor receptor-targeted therapy? J. Clin. Oncol. 2010, 28, 4769-4777.

251. Zlobec, I.; Bihl, M.P.; Schwarb, H.; Terracciano, L.; Lugli, A. Clinicopathological and protein characterization of braf- and k-ras-mutated colorectal cancer and implications for prognosis. Int. J. Cancer 2010, 127, 367-380.

252. Krueger, K.E.; Srivastava, S. Posttranslational protein modifications: Current implications for cancer detection, prevention, and therapeutics. Mol. Cell. Proteomics 2006, 5, 1799-1810.

253. Karve, T.M.; Cheema, A.K. Small changes huge impact: The role of protein posttranslational modifications in cellular homeostasis and disease. J. Amino Acids 2011, 2011.

254. Drolet, D.W.; Moon-McDermott, L.; Romig, T.S. An enzyme-linked oligonucleotide assay. Nat. Biotechnol. 1996, 14, 1021-1025.

255. Lin, M.-Y.; Lu, Y.-P.; Mihai Grumezescu, A.; Han Ho, F.; Kao, Y.-H.; Yang, Y.-S.; Yang, C.-H. Tumor marker detection by aptamer-functionalized graphene oxide. Curr. Org. Chem. 2013, 17, 132-136.

256. Gold, L.; Ayers, D.; Bertino, J.; Bock, C.; Bock, A.; Brody, E.N.; Carter, J.; Dalby, A.B.; Eaton, B.E.; Fitzwater, T.; et al. Aptamer-based multiplexed proteomic technology for biomarker discovery. PLoS ONE 2010, 5, doi:10.1371/journal.pone.0015004. 
257. Ostroff, R.M.; Bigbee, W.L.; Franklin, W.; Gold, L.; Mehan, M.; Miller, Y.E.; Pass, H.I.; Rom, W.N.; Siegfried, J.M.; Stewart, A.; et al. Unlocking biomarker discovery: Large scale application of aptamer proteomic technology for early detection of lung cancer. PLOS ONE 2010, 5, doi:10.1371/journal.pone.0015003

258. Xiong, X.; Lv, Y.; Chen, T.; Zhang, X.; Wang, K.; Tan, W. Nucleic acid aptamers for living cell analysis. Annu. Rev. Anal. Chem. 2014, 7, 405-426.

259. Zhou, W.; Huang, P.-J.; Ding, J.; Liu, J. Aptamer-based biosensors for biomedical diagnostics. Analyst 2014, 139, 2627-2640.

260. Toh, S.Y.; Citartan, M.; Gopinath, S.C.B.; Tang, T.-H. Aptamers as a replacement for antibodies in enzyme-linked immunosorbent assay. Biosens. Bioelectron. 2015, 64, 392-403.

(C) 2015 by the authors; licensee MDPI, Basel, Switzerland. This article is an open access article distributed under the terms and conditions of the Creative Commons Attribution license (http://creativecommons.org/licenses/by/4.0/). 